\title{
Untethering the Nuclear Envelope and Cytoskeleton: Biologically Distinct Dystonias Arising from a Common Cellular Dysfunction
}

\author{
Nadia A. Atai, ${ }^{1,2,3,4}$ Scott D. Ryan, ${ }^{5}$ Rashmi Kothary, ${ }^{5}$ \\ Xandra O. Breakefield, ${ }^{1,2,3}$ and Flávia C. Nery ${ }^{1,2,3}$ \\ ${ }^{1}$ Neuroscience Center, Department of Neurology, Massachusetts General Hospital, East, Boston, MA 02114, USA \\ ${ }^{2}$ Center for Molecular Imaging Research, Department of Radiology, Massachusetts General Hospital, East, Boston, MA 02114, USA \\ ${ }^{3}$ Program in Neuroscience, Harvard Medical School, Charlestown, Boston, MA 02129, USA \\ ${ }^{4}$ Department of Cell Biology and Histology, Academic Medical Center (AMC), University of Amsterdam, \\ 1105 AZ Amsterdam, The Netherlands \\ ${ }^{5}$ Ottawa Hospital Research Institute, Department of Cellular and Molecular Medicine, Ottawa, ON, Canada KIH 8L6
}

Correspondence should be addressed to Flávia C. Nery, nery.flavia@mgh.harvard.edu

Received 31 August 2011; Revised 12 December 2011; Accepted 8 January 2012

Academic Editor: Gerhard Wiche

Copyright ( $) 2012$ Nadia A. Atai et al. This is an open access article distributed under the Creative Commons Attribution License, which permits unrestricted use, distribution, and reproduction in any medium, provided the original work is properly cited.

\begin{abstract}
Most cases of early onset DYT1 dystonia in humans are caused by a GAG deletion in the TOR1A gene leading to loss of a glutamic acid $(\Delta E)$ in the torsinA protein, which underlies a movement disorder associated with neuronal dysfunction without apparent neurodegeneration. Mutation/deletion of the gene (Dst) encoding dystonin in mice results in a dystonic movement disorder termed dystonia musculorum, which resembles aspects of dystonia in humans. While torsinA and dystonin proteins do not share modular domain architecture, they participate in a similar function by modulating a structural link between the nuclear envelope and the cytoskeleton in neuronal cells. We suggest that through a shared interaction with the nuclear envelope protein nesprin-3 $\alpha$, torsin A and the neuronal dystonin-a2 isoform comprise a bridge complex between the outer nuclear membrane and the cytoskeleton, which is critical for some aspects of neuronal development and function. Elucidation of the overlapping roles of torsinA and dystonin-a2 in nuclear/endoplasmic reticulum dynamics should provide insights into the cellular mechanisms underlying the dystonic phenotype.
\end{abstract}

\section{Introduction}

1.1. Human DYT1 Dystonia. Dystonia is the third most common movement disorder in humans, following essential tremor and Parkinson's disease. Dystonia is characterized by involuntary sustained muscle contractions that lead to twisting movements and abnormal postures [1] and comprise a heterogeneous set of clinical syndromes (for review see $[2,3])$. Dystonias are generally classified on the basis of the bodily distribution of symptoms (focal, segmental, or generalized), age of disease onset (early or late), and etiology (primary or secondary). Dystonias are classified as primary when the symptoms develop spontaneously in the absence of any apparent cause or associated disease and as secondary when symptoms result from other disease states, for example Parkinson's disease or brain injury. Dystonia can be caused by dysfunction in many regions of the human brain, usually without detectable neurodegeneration. However, in a few hereditary dystonia conditions and secondary cases of dystonia, neurodegeneration may be involved.

Many primary dystonias have a hereditary component, and once the abnormal movements appear they do not remit. Twenty different genes have been implicated in various types of dystonia, many of which are inherited as autosomal dominant traits with reduced penetrance $[4,5]$. Therefore, the identification of common molecular pathways that underlie multiple dystonia subtypes would improve our ability to develop new treatment strategies with wide therapeutic applications. Among the known human dystonia genes, the TOR1A gene, encoding the torsinA protein, is responsible for early-onset, torsion dystonia (DYT1) and has been the most studied type of dystonia [6]. Historically, DYT1 dystonia was 
referred to as dystonia musculorum deformans and thought to be inherited as an autosomal recessive condition $[7,8]$.

DYT1 is a severe form of hereditary, generalized dystonia [9]. Most cases are now known to be caused by a dominantly inherited in-frame GAG deletion in the TOR1A gene, with only a few other isolated mutations in this gene associated with a dystonic phenotype [10-12]. The GAG deletion results in loss of a glutamic acid residue in the protein product, referred to as torsin $A \triangle E$. DYT1 patients are all heterozygous gene carriers, with no homozygotes harboring the mutation identified in humans to date.

1.2. TorsinA Findings. Since the discovery of the TOR1A gene [6], a number of cellular processes have been associated with torsinA, albeit the specific molecular mechanism through which mutated torsinA leads to DYT1 dystonia remains unclear. Torsin A is predominantly localized in the contiguous lumen of the endoplasmic reticulum (ER) and the nuclear envelope (NE). However, when the mutant form of torsin $\mathrm{A}$, torsin $\mathrm{A} \Delta E$, is overexpressed, it concentrates in the perinuclear space of the NE, forming inclusions in both neuronal and nonneuronal cells [13-16]. In the few studies published on neuropathology in DYT1 brains, abnormalities in torsinA localization or signs of inflammation/neurodegeneration have not been reported $[17,18]$. In a small sample set, dopaminergic cell bodies in the substantia nigra appeared to be enlarged in DYT1 patients compared to normal individuals [19]. In one report, pathological abnormalities were described in brains of DYT1 patients, included ubiquitin and torsinA-positive inclusions in neurons in the brainstem, ubiquitin-positive inclusions in pigmented neurons in the substantia nigra and locus coeruleus, as well as elevated levels of tau, a protein associated with microtubules (MTs) [20]. Similar inclusions have been observed in some of the DYT1 mouse models generated by transgenic overexpression of human torsin $A \Delta E$ [21-23].

In mouse models of DYT1 dystonia, including homozygous knock-out of torsin $A$ and knock-in of torsin $A \Delta E$, marked morphological changes have been found in the NE of neurons [24]. These findings suggest that neurons are especially dependent on the function of torsinA in defining nuclear structure, which, in turn, may affect movement of the nucleus in relationship to the cytoskeleton during neuronal migration in developmental phases. TorsinA interacts with proteins that span the inner nuclear membrane (INM), specifically lamina-associated polypeptide 1 (LAP1) [25] and Sad1 and UNC84 domain containing 1 (SUN1) [26], as well as proteins in the outer nuclear membrane (ONM), such as the nesprins (nuclear envelope spectrin repeat) [27]. LAP1 is a type II membrane protein consisting of three variants, LAP1A, 1B, 1C, which play a crucial role in providing attachment of lamins to the INM [28]. LAP1 depletion causes similar NE abnormalities to those observed in torsinA-null cells [29]. Furthermore, the absence of SUN1 results in movement of torsin $A$ and torsin $A \triangle E$ away from the NE into the ER. In contrast, LAP1 is not required for torsinA $\triangle E$ localization to the NE. SUN proteins have a nuclear domain that mediates interaction with lamins and an NE lumenal domain that interacts with nesprin proteins, thereby forming the "linker of nucleoskeleton and cytoskeleton" (LINC) complex [30-33]. Nesprin proteins are exclusively ONM cytoskeletal linkers mediating interactions of the nucleus with various cytoskeletal structures, such as actin filaments (AFs), intermediate filaments (IFs), and MTs, as well as associated motor proteins, such as kinesin-1/2, dynein, and dynactin [34]. Therefore, torsinA and its NE interacting proteins may have a role in modulating the link between the $\mathrm{NE}$ and the cytoskeleton, enabling the nucleus to negotiate its position within the cell during polarization, migration, and differentiation.

1.3. Murine Dystonia Musculorum (dt). Mutations in the dystonin $(D s t)$ gene in mice result in a movement disorder phenotypically resembling some aspects of early-onset torsion dystonia in humans. These mice were therefore termed $d t[35,36]$. While heterozygous $d t$ mice appear to be normal throughout life, homozygous $d t$ mice exhibit an early-onset phenotype. Mice are asymptomatic at birth, but by postnatal days $10-12$ they begin to exhibit signs of twitching, writhing, and uncoordinated movements. The $d t$ mice are typically characterized as having a sensory neuropathy with associated neurodegeneration, although motor neuron abnormalities and some brain involvement have recently been identified [37].

\subsection{Parallels between Human DYT1 and Murine dt Dystonias.} Although there are many differences between human DYT1 dystonia, a dominantly inherited brain disorder with no marked neuropathology, and murine $d t$ dystonia, a recessively inherited disorder primarily involving neurodegeneration in the peripheral nervous system, these forms of dystonia share common elements at the level of cellular dysfunction. A comparison of these disorders was initially confounded by the fact that aberrations in function of the human homologue of the Dst mouse gene are associated with skin blistering, as well as neuropathologies, and not with human dystonia [38-40].

Surprisingly, recent molecular and cellular studies on the functions of dystonin and torsinA have provided interesting molecular parallels between the potential roles of these proteins in interactions between NE/ER and the cytoskeleton. Both torsin $\mathrm{A}$ and the dystonin-a2 neuronal isoform have been reported to interact with nesprin-3 $\alpha[27,41]$ located in the ONM of the NE [42]. Nesprin-3 $\alpha$ interacts with the multifunctional cytoskeletal linker plectin, which consists of various isoforms that facilitate interaction with IFs [42]. Plectin is highly expressed in various cell types and plays a major role in cellular cytoskeletal organization and dynamics [43]. Plectin interaction with nesprin- $3 \alpha$ serves to link the NE membrane and IFs, which in turn are linked to AFs and MTs through members of the spectraplakin protein family $[42,43]$.

Consolidation of the existing literature on subcellular localization, protein interactions, and loss of function behavioral correlates led us to speculate that torsinA and dystonina2 may both participate in protein complexes associated 
with membranes of the NE/ER and the cytoskeleton. In this paper, we present current knowledge of torsin and dystonin proteins, including their functional similarities and differences, in order to highlight common mechanisms that may underlie different forms of dystonia through disruption of the link between the NE/ER and cytoskeleton that may impair neuronal development and function.

\section{Torsin-Related Proteins}

Torsin proteins are members of the $\mathrm{AAA}^{+}$superfamily of ATPases [44]. Most $\mathrm{AAA}^{+}$proteins form oligomeric complexes (typically six subunit rings) obtaining energy from ATP hydrolysis and acting as chaperone-like modules [45]. $\mathrm{AAA}^{+}$proteins are involved in different cellular processes such as protein folding, membrane trafficking, vesicle fusion, and cytoskeleton dynamics [45-47]. Other activities associated with $\mathrm{AAA}^{+}$proteins include peroxisome biogenesis, assembly of mitochondrial proteins, cell cycle control, mitotic spindle formation, cytoskeleton interactions, vesiclemediated secretion, signal transduction, and transcriptional regulation [48-51]. The $\mathrm{AAA}^{+}$domain of torsinA contains the Walker A motif (also known as the P-loop-ATP binding domain), the Walker B motif (ATP hydrolysis), and the ATP sensing motifs (sensor I and sensor II) [52, 53], and six prominently conserved cysteine residues (Figure 1). Their location in the lumen of the NE/ER and cysteine residues in the $\mathrm{AAA}^{+}$domain distinguish these torsin family members from other $\mathrm{AAA}^{+}$proteins $[52,54]$.

Two structural models of human torsinA are based on the crystal structure of orthologues in bacteria, ClpA [52] and ClpB [53] proteases, also members of the $\mathrm{AAA}^{+}$ ATPase superfamily that form homohexameric structures. Both structures suggest that torsin $\mathrm{A}$ is composed of two subdomains, a $\mathrm{N}$-terminal $\alpha / \beta$ subdomain and a $\mathrm{C}$-terminal $\alpha$-helical subdomain. The latter subdomain is the region containing mutations in DYT1 dystonia patients $[6,10,12]$. The $\triangle \mathrm{GAG}$ deletion associated with most cases of DYT1 dystonia removes a glutamic acid residue from an $\alpha$-helix in the C-terminal subdomain [53]. Although mutant torsinA is presumed to be able to associate with wild-type torsinA subunits in six subunit rings, its altered structure may serve to decrease activity of the hexamer [55]. ATP-dependent Clp proteases are involved in nonlysosomal removal of damaged or misfolded proteins in bacteria $[56,57]$. In mammalian cells mutant or misfolded proteins in the ER are eliminated by ER-associated degradation (ERAD) with torsinA facilitating exit of proteins to the cytoplasm where they are degraded by the ubiquitin-proteasome system [58]. Curiously, $\mathrm{ClpA} / \mathrm{ClpB}$ and most members of the $\mathrm{AAA}^{+}$protein family present a Walker A consensus GxxGxGK [T/S] motif, which contains an essential lysine that supports binding of nucleotides, whereas torsinA contains a noncanonical Walker A sequence, GxxGxGKN [47]. When the threonine in the Walker A motif was replaced with asparagine in the ClpB protease, so as to make it more similar to torsinA, the ATPase activity was partially inhibited. However, this did not affect the ability of $\mathrm{ClpB}$ to form hexamers. The noncanonical
Walker A sequence introduced into ClpB induced preferential binding of ADP rather than ATP and reduced its chaperone activity in vitro and in vivo [47]. This suggests that torsin proteins might utilize distinct mechanisms to couple the ATPase cycle with their substrate-remodeling activity.

2.1. The Four Torsin Proteins in Mammals. Four genes encoding torsin family members have been identified in mammals: torsin $A$, torsin $B(85 \%$ similar to torsin $A)$, torsin2, and torsin3 (67\% and $61 \%$ similar to torsinA, resp.) [59] (Figure 1). All four proteins share the core $\mathrm{AAA}^{+}$domain $[52,53,60]$. Torsin A and torsinB genes (TOR $1 A$ and TOR $1 B$, resp.) are adjacent to each other in opposite orientations on chromosome 9q [59]). The torsin 2 gene (TOR2) is located on the same chromosome in nearby region. These three torsin genes (TOR1A, TOR1B, and TOR2) possess five exons. In contrast, the torsin 3 gene (TOR3) is located on chromosome $1 \mathrm{q}$ and has six exons. TorsinA has been the most extensively studied due to its role in DYT1 dystonia. The glutamic acid deletion at position $302 / 303$ in exon 5 of torsinA is responsible for about $80 \%$ of cases in the Ashkenazic Jewish population and about $40 \%$ in the general population. Five other variations have been found that change the amino acid sequence of torsinA: F205I in exon 3 [11] with the rest in exon 5, including R288Q [12], a 4 bp deletion that causes a frameshift and truncation starting at residue 312 [61], and an 18 bp deletion $(\Delta \mathrm{F} 323-\mathrm{Y} 328)[10]$, but the pathogenicity of these sequence variants has yet to be established. In addition, there is a polymorphism in the coding sequence for residue 216 encoding aspartic acid (D) in $88 \%$ and histidine $(\mathrm{H})$ in $12 \%$ of alleles in control populations [10], with the D216H polymorphism influencing the penetrance of DYT1 dystonia [62].

Torsin A is a 332-amino-acid protein that contains an $\mathrm{N}$-terminal ER signal sequence (SS) and a 20-amino-acid hydrophobic region followed by a conserved $\mathrm{AAA}^{+}$domain (Figure 1). The SS and glycosylation state of torsinA are consistent with its location in the ER/NE, with the hydrophobic N-terminal sequence apparently retaining it in this location $[13,63-65]$. However, with the exception of torsinB, which has very similar characteristics to torsin A $[63,66]$, the subcellular localization of torsin 2 and torsin 3 remains poorly characterized. It was recently reported that digestion of glycosylated residues reduces the molecular weight of all four torsins in whole-cell preparations [60], indicating that all reside in the ER or at least pass through that compartment and may have overlapping functions, as do torsinA and torsinB [29].

Although torsinA is widely expressed in human tissue, it appears to have its most critical role in the central nervous system (CNS), where it is present at high levels during development $[67,68]$. In adult brains, high levels of torsinA expression are found in specific neuronal populations, such as dopaminergic neurons in the substantia nigra pars compacta, interneurons in the striatum, and neurons in the cerebral cortex, thalamus, hippocampus, cerebellum, midbrain, pons, and spinal cord [19,69-73]. TorsinA has been implicated in several cellular pathways including NE integrity 

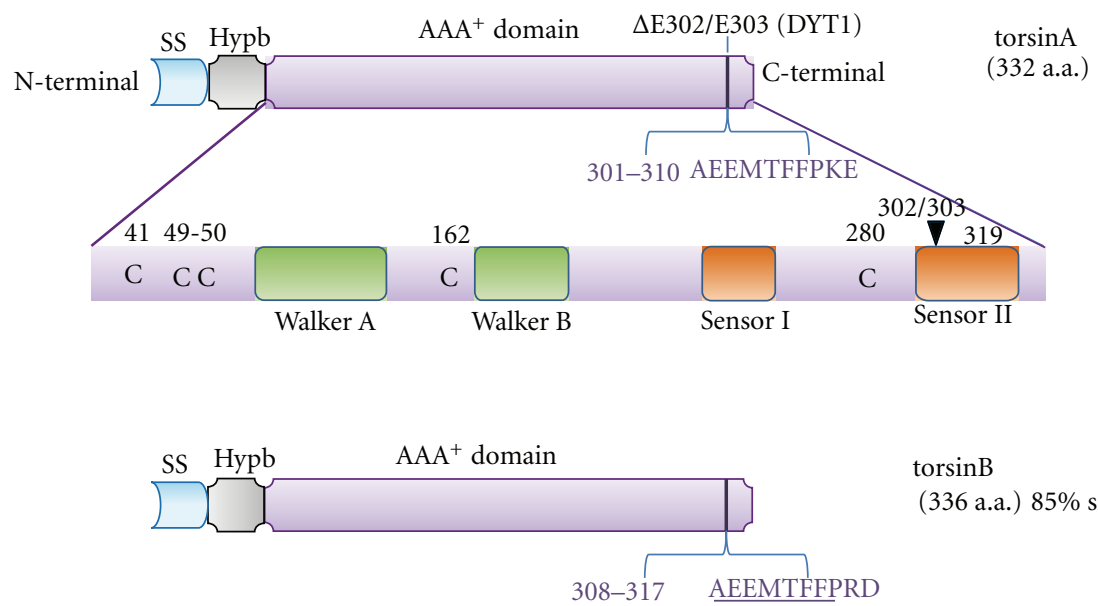

torsin $B$

(336 a.a.) $85 \%$ similar

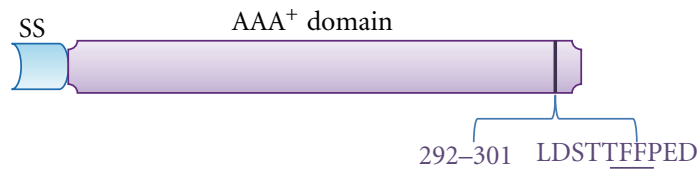

torsin 2

(321 a.a.) 67\% similar

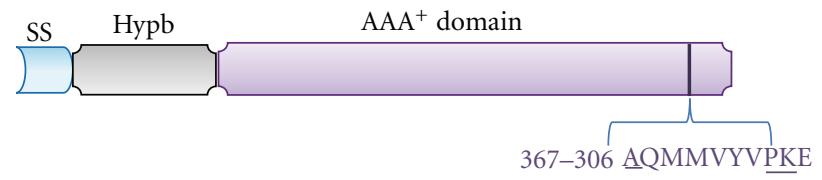

torsin 3

(397 a.a.) 61\% similar

FIGURE 1: Schematic diagram of the $\mathrm{AAA}^{+}$torsin protein family. The key features of torsinA, torsinB, torsin2, and torsin3 are shown, including the signal sequence (SS; turquoise), hydrophobic domain (Hypb; grey), and $\mathrm{AAA}^{+}$domain (purple). The AAA ${ }^{+}$domain of torsin A, illustrated in more detail, consists of Walker A/B (green) motifs, sensor I/II (orange) motifs, and six conserved cysteines (C). Also, the total number of amino acids (a.a.) for each protein and the overall percentage similarity with torsinA are indicated. In torsin2, the Hydb domain is absent and torsin 3 has a longer Hydb domain. The 10 a.a. region in torsinA in which the glutamic acid deletion underlying DYT1 dystonia occurs is shown in detail. Conserved a.a. residues in this region in other members of the torsin family are underlined (figure revised from Jungwirth et al. [26] and Zhu et al. [54]).

[14-16, 24, 26, 29], cytoskeleton organization [27, 74-76], nuclear polarity [27] (as well as the nematode homologue, OCC-5 [77]), chaperone functions [78-82], degradation of misfolded proteins $[58,83]$, ER stress sensitivity [58, 8487], dynamics of secretory and synaptic vesicles [88-92], and modulation of dopamine (DA) neurotransmission [93-107].

The second most investigated torsin protein, torsinB, is highly expressed in the lung, placenta and testis, with low levels in the brain $[29,60,63]$. Immunoprecipitation studies indicated that torsin $A$ and torsin $B$ associate with each other [63] and have a similar distribution in nonneuronal cells [29, $60,66]$. Mutations or other pathologies in human disease have not been reported for torsinB. Similar to torsinA, torsinB expression is temporally and spatially regulated, with torsin $B$ expression in the developing brain peaking after that of torsinA $[68,108]$. The low expression of torsinB relative to torsin $\mathrm{A}$ in the brain and the high expression of torsinB in other tissues may explain why the brain is selectively affected by mutant torsinA and why nonneuronal tissue are protected from torsinA dysfunction in DYT1 patients [29].

The other mammalian torsin members, torsin2 and torsin3, share the core $\mathrm{AAA}^{+}$domain and the functionally important region affected by the DYT1 mutation (Figure 1)
$[52,53]$. Torsin 3 contains an extended amino terminus, and torsin2 lacks a specific Hypb between the SS and the AAA domain (Figure 1). To determine whether other torsin family members can change their location in cells, a mutation in the Walker B motif (E171Q, ATP-bound state) of the AAA domain was generated in different members. In torsin $A$ this mutation leads to a substrate-trap state with defects in ATP hydrolysis and accumulation of torsin $\mathrm{A}$ in the perinuclear region [16]. Mutated Walker B motifs in torsinB (E178Q) and torsin2 (E162Q) also led to movement out of the ER and into the NE region, while that in torsin3 (E236Q) did not change its location, which remained predominantly in the ER. In contrast to other torsin family members, torsin 3 is an interferon-regulated protein [109] and may have distinct biological function(s). Notably, three of four torsin family members (torsin $\mathrm{A}$, torsinB, and torsin2) operate within the $\mathrm{NE}$, making them candidates for involvement in nuclearcytoskeleton links.

2.2. TorsinA and Its Nonmammalian Orthologues. Besides $\mathrm{ClpA}$ and $\mathrm{ClpB}$, which are the torsin A orthologues found in bacteria, yeast, and plants [47], other coding sequences 
related to the TOR1A gene have been found in nonmammalian organisms, including Drosophila (Torp4a, dtorsin), nematodes (tor-1, tor-2, and OOC-5) and zebrafish (tor$\sin C)[55]$.

Drosophila may be a viable model for providing insights into human dystonia. Loss of dtorsin or expression of human mutant torsin A, torsin $A \Delta E$, leads to abnormal motor behavior in Drosophila larvae [107, 110]. Interestingly, dtorsinnull flies have decreased levels of DA and movement can be normalized by feeding DA to larvae or by expressing human torsin A [107]. Dtorsin is 34\% identical to human torsin A and is predominantly localized in the ER, but also found in the NE. Although neural degeneration caused by the loss of torsin function has not previously been reported in other organisms, downregulation of dtorsin resulted in increased age-related retinal degeneration in Drosophila [80]. In parallel, overexpression of dtorsin protected the retina from degeneration.

Three torsin-like gene products are predicted in the nematode Caenorhabditis elegans (C. elegans) (tor-1, tor-2, and OOC-5). Ectopic overexpression of either tor-2 and OOC-5 or human torsinA resulted in a reduction of polyglutamine repeat-induced protein aggregation in C. elegans, supporting a chaperone function [94]. Moreover, mutant forms of tor2 were unable to ameliorate aggregation, and tor- 2 and ubiquitin colocalized at sites of protein aggregation. The OOC- 5 protein is also located in the ER/NE, and loss of OOC-5 disrupts nuclear rotation during early embryogenesis [77]. This nuclear rotation is mediated by cytoskeletal links between the nuclear centrosome complex and the cortical surface of the embryo [111]. In parallel, absence of torsinA interferes with the positioning of nuclei within migrating mouse fibroblasts, thus delaying initiation of migration [27]. It has also been hypothesized that the sensor II motif in torsin proteins (Figure 1) acts as a redox-regulated sensor. The oxidation of the cysteine in the sensor II motif of OOC-5 disrupts its function [52], and, in parallel, the redox state of this motif in torsin A influences its association with binding partners, LAP1 and lumenal domain like LAP1(LULL1) [54]. Both ATPase activity and protein binding to torsins are regulated by the redox state of the ER, consistent with their proposed role as ER chaperone proteins involved in processing of membrane proteins and in the ER stress response $[58,86,88,93]$.

\section{Dystonin and the Plakin Family of Cytoskeletal Linker Proteins}

The eukaryotic cytoskeleton comprises three cytoskeletal networks that include MTs, AFs, and IFs. These networks rely upon cytoskeletal cross-linking proteins, known as plakins, such as dystonin, for maintenance of their functional integrity and interactions. Cytoskeletal linker proteins are critical regulators of cellular processes ranging from vesicular transport and maintenance of organelle integrity to mitosis and cell death [112]. As such, impairment of cytoskeletallinker function impacts cell viability, development and a variety of cellular functions and has been associated with several organelle-specific stress pathways $[41,113,114]$.

3.1. Plakins as Cytoskeletal Linkers. Members of the plakin family of cytoskeletal proteins are critical in maintaining the function and integrity of tissues. For example, they link junctional complexes between cells (desmosomes and hemidesmosomes) with the cytoskeletal network within the cells (for review see [114]). A common structural element conserved in most family members is the plakin domain, comprising six antiparallel segments arranged in an $\alpha$-helical fashion [115]. Numerous plakin proteins have been identified in mammalian central nervous system (CNS), including dystonin (also known as bullous pemphigoid antigen 1 (BPAG1)) [8, 116], MT-actin cross-linking factor 1 (MACF1), (also known as actin-cross linking factor 7 (ACF7) ) [112, 117-119], plectin (isoforms 1a, 1b, and 1c, 1e, 2a, and 3a) [112], desmoplakin and periplakin [120]. Both plectin and desmoplakin have been demonstrated to interact directly with IF [121]. Plectin is one of the most versatile and ubiquitously expressed plakins. The association of plakins with IFs changes depending on the phosphorylation state of serine residues in the carboxy-terminal segment of the plakin, suggesting that this interaction may be regulated within cells [112]. Recently, it has been suggested that plectin serves as a nucleation and assembly center for the de novo formation of IFs networks and acts in turnover of focal adhesions [122]. The abundance of spectrin repeats (SRs), as found in several plakin family members, has resulted in their further subclassification as spectraplakins, namely, dystonin and MACF1 (mammalian), short stop (Drosophila), and variable abnormal morphology (VAB; C. elegans) [115, 123]. Mutations in plakins are associated with a variety of neurological disorders in humans [39, 124-126], while in animals only a mutation in Dst results in a neurological phenotype. Extensive structural homology exists among mammalian spectraplakins, including the SR domains, which act as docking stations for cytoskeletal elements [127], the actin-binding domain (ABD), and MT binding domain (MTBD) $[115,116$, $118,128,129]$. The multidomain nature of these proteins facilitates their function in linking cytoskeletal elements and bridging them with junctional complexes. The cellular localization and predicted activity of dystonin implicate it in functions of the peripheral sensory and motor nervous system.

3.2. Dystonin Isoforms Generated by Alternative Splicing. The Dst is a large gene $(\sim 400 \mathrm{~kb})$ in mice and gives rise to three tissue-specific dystonin protein isoforms, namely, dystonin-e (epithelial isoform, $\sim 315 \mathrm{kDa}$ ), dystonin-b (muscle isoform, $\sim 834 \mathrm{kDa}$ ), and dystonin-a (neuronal isoform, $\sim 615 \mathrm{kDa}$ ) (Figure 2(a)) [8, 128, 130, 131]. Dystonin-e serves as an autoantigen in the skin blistering disease, bullous pemphigoid (BP) in humans and a mutation affecting this isoform results in a similar defect in mice. Loss of function of dystonin-a is believed to be causal in $d t$ sensory/motor neuropathy in mice $[8,37,131-133]$. Three neuronal isoforms of dystonin-a are generated by alternative splicing, namely, dystonin-a1, 


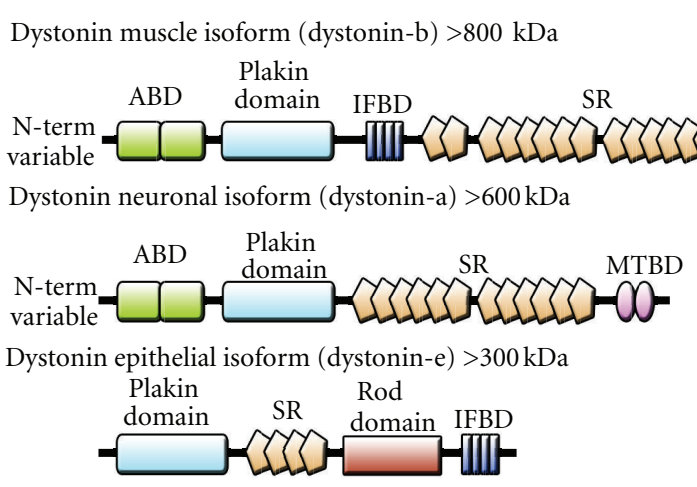

(a)

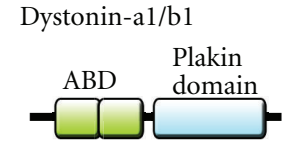

Dystonin-a2/b2

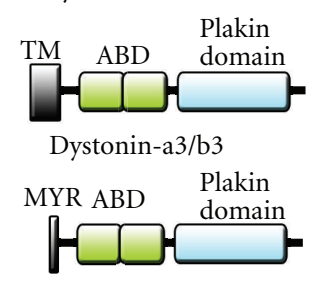

(b)

FIGURE 2: Structural representation of dystonin protein isoforms. (a) Illustration of the modular domain structure of tissue specific dystonin isoforms. Three tissue-specific isoforms have been identified; muscle (dystonin-b), neuronal (dystonin-a), and epithelial (dystonin-e). (b) Dystonin- $\mathrm{a}$ and $\mathrm{b}$ isoforms vary at the $\mathrm{N}$-terminus, resulting in three distinct isoforms. The isoform 1 variant possesses a sequence coding for an $\mathrm{ABD}$ at the $\mathrm{N}$-terminus. The isoform 2 variant contains sequence coding for a highly conserved $\mathrm{N}$-terminal TM domain, while the isoform 3 variant contains sequence coding for a conserved MYR motif.

dystonin-a2, and dystonin-a3 [134] (Figure 2(b)). These isoforms share an $\mathrm{ABD}$ sequence, an extensive coiled-coil region, and a C-terminal MTBD allowing for interactions with actin and MTs, thus facilitating their function as cytoskeletal linkers [128]. They differ on the basis of unique $\mathrm{N}$-terminal regions that dictate their subcellular location. Specifically, dystonin-a1 possesses a short N-terminal domain that includes an ABD localizing it to AFs, dystonin-a2 possesses a transmembrane (TM) domain localizing it to the $\mathrm{NE}$ and perinuclear membranes, and dystonin-a3 possesses a putative MYR motif, aiding in anchoring it to the plasma membrane (Figure 2(b)) $[135,136]$. The unique TM domain of dystonin-a2 distinguishes it from other spectraplakins. While other spectraplakins link neurofilaments (NFs) to MTs, AF or junctional complexes, dystonin-a2 links AFs and MTs with membranes of the ER, Golgi-apparatus and nucleus. Moreover, mutations in dystonin-a2 lead to induction of ER chaperone proteins and the unfolded protein response, which are believed to contribute to degeneration of both sensory and motor neurons $[8,37,41,137]$.

3.3. Dystonin Function in Neurons. Spectraplakins associate with MTs via two conserved domains: the growth arrestspecific 2- (Gas2-)related domain and its adjacent carboxy terminal tail region $[118,129,138]$. While the Gas2-related domain aligns along MT shafts and promotes MT stabilization $[129,138]$, the carboxy terminus of spectraplakin family members MACF1, and short stop bind to the MT plus-endbinding protein 1 (EB1) and localize at growing MT ends [139-141], establishing spectraplakins as putative plus-tipinteracting proteins. Direct interactions between EB1 and dystonin have not been reported, but the conserved modular domains between dystonin-a2 and MACF1 suggest that dystonin may be involved in MT polymerization. Both dystonina2 and MACF1b have been found in the Golgi apparatus, and overexpressed dystonin-a2 colocalizes with the cisGolgi protein GM130, suggesting a functional role in Golgi apparatus-mediated MT nucleation [119, 136, 142]. Other MT-associated proteins, such as MAP1B and clathrin, have been shown to promote MT polymerization and stability when localized to the Golgi apparatus $[143,144]$. Dystonina2 has been shown to interact with both MAP1B and clathrin via the modular plakin domain [145]. Plus-end MT polymerization from the Golgi apparatus toward the leading edge of the cell supports a role in cell migration [146, 147], and mutations in MT-associated proteins, including MAP1B and MACF1 cause defects in neuronal migration and cortical development $[125,148,149]$. Although no developmental migration defects have been reported in $d t$ neurons to date, such deficits have been noted in epithelial cells lacking the smaller epithelial isoform (dystonin-e) [138].

Spectraplakins have also been implicated in the ultrastructural organization of organelles. For example, the organization of the Golgi apparatus complex is dependent on MACF1b, which shares a similar domain structure with neuronal dystonia-a2 $[118,119]$. Chemical dispersion of the Golgi apparatus results in redistribution of MACF1b to the ER, while reduced levels of MACF1b induce Golgi apparatus fragmentation. Localization of MACF1b to the Golgi apparatus is mediated by its $\mathrm{N}$-terminal plakin domain [119]. This domain is conserved in dystonin-a2 and oriented adjacent to the TM domain that positions the protein along perinuclear membranes $[41,136]$. As such, dystonin-a2 appears to be a critical modifier of perikaryal structures and may influence functions of the ER, Golgi apparatus, and NE. Compromised organization of the ER, Golgi apparatus, and MT network would no doubt influence protein processing through the secretory pathway. Molecular interaction studies have implicated dystonin in regulation of the dynein motor complex through interaction with dynactin and the endosomal vesicle protein, retrolinkin [150,151]. Defective fast axonal transport has also been reported in the sciatic nerves of phenotypic $d t^{27 J}$ mice in both orthograde and retrograde directions [152]. Indeed, cytoskeletal linkers have a general role in mediating axonal transport by regulating 
organelle organization and movement in addition to stabilizing the cytoskeleton. Collectively, these findings show that functional impairment of sensory and motor neurons can result from defects in cytoskeletal mediated intracellular trafficking.

\section{Studies in Humans and Mice Models with Mutations in TOR1A and Dst}

4.1. Human DYT1 Dystonia: A CNS Movement Disorder. Dystonia has been considered to be primarily a disorder of the basal ganglia since patients with secondary dystonia commonly exhibit lesions within structures associated with the basal ganglia, including caudate, putamen, globus pallidus, and thalamus [153-155]. However, substantial evidence also implicates cerebellar and brainstem pathology in cases of primary and secondary dystonia [3, 156, 157]. Hypermetabolic signals within premotor cortex and cerebellum have been found in patients with primary dystonias, including hemidystonia, exercise-induced paroxysmal dystonia, and DYT1 dystonia [158-161]. Symptoms of dystonia have also been reported in familial forms of ataxia, where the degeneration appears to be limited to the cerebellum and brainstem [162]. Although many interconnected brain regions can be affected in human dystonia, there does not appear to be any pathophysiology in peripheral sensory or motor neurons. This stands in contrast to the $d t$ dystonic motor syndrome in mice where the peripheral nervous system is primarily affected with marked pathology. It has been speculated that the high expression of other members of the plakin family in the brain, MACF1 in particular, may compensate for dystonin loss in the CNS of $d t$ mice $[119,125,163]$.

Genetic mouse models of DYT1 dystonia have been created to better understand the neurobiological basis of dystonia (Table 1). However, mutations that result in dystonia in humans do not generate an obvious dystonic phenotypic in mice. Mouse models of dystonia also do not show any obvious evidence of neuronal loss, although in some models the levels of striatal DA and its metabolites were reduced and animals showed some motor abnormalities (Table 1), such as hyperactivity, circling behavior, deficits in beam walking, and reduced motor learning [21, 97, 104, 164, 165]. Some models of dystonia in rats and mice implicate abnormal cerebellar signaling, including Purkinje cells and deep cerebellar nuclei [166-170]. In addition, selective elimination of the cerebellar output in some mouse and rat models served to block the dystonic symptoms [171-174].

4.2. Dystonia Musculorum: A Peripheral Nervous System Movement Disorder in Rodents. The $d t$ mouse arose spontaneously as a recessively inherited mutation with a severe movement disorder that appeared to resemble dystonia in humans [35]. This mouse disorder develops as a progressive ataxia, due to the degeneration of the sensory neurons, and appears similar to generalized dystonia with twisting movements of the neck, paddling motions of the limbs, and abnormal posturing of limbs and trunk. The disease progresses rapidly and $d t$ mice die in the third week of life of unknown causes $[8,177]$. Accumulation of NF tangles within sensory neurons of $d t$ mice is a pathological feature of the disease [36, 179-182]. In addition, an abnormal accumulation of hyperphosphorylated NFs is found in the perikarya and proximal regions of axons of spinal motor neurons [36]. Peripheral $d t$ pathologies have been documented in motor neurons, skeletal muscle, and Schwann cells, but degeneration is most prominent in dorsal root ganglion sensory neurons [36, 37, 183, 184]. Interestingly, $d t$ mice also exhibit lesions within several brain regions, including basal ganglia and cerebellum [37, 185, 186]. Several $d t$ mouse models exist through spontaneous mutations $\left(d t^{27 J}, d t^{A l b}\right)$, chemically induced mutations $\left(d t^{37 J}\right.$, $\left.d t^{33 J}\right)$, targeted alleles $\left(d t^{\text {tm } 1 E f u}\right)$, and transgenic insertions $\left(d t^{T g 4}\right)[130,131]$ (Table 1). While only three $d t$ mutations $\left(d t^{T g 4}, d t^{t m 1 E f u}\right.$, and $\left.d t^{A l b}\right)$ have been characterized at the DNA level, $d t^{T g 4}$ and $d t^{27 J}$ are allelic but do not complement $[113,132,137]$. While it is unresolved as to whether loss of a single isoform or combination of isoforms is responsible for neuronal loss, defects in nucleoskeletal/cytoskeletal function are paramount in these $d t$ models.

4.3. Dystonin-Related Disorders in Humans. In humans, dystonin-e was initially characterized under its pseudonym BPAG1e as a major autoantigen in the skin blistering disease, BP [38]. In keratinocytes, dystonin-e links keratin-containing IFs to hemidesmosomes [187]. Mutation of the plakin family member plectin results in a similar phenotype in humans termed epidermolysis bullosa simplex $[188,189]$. The original characterization of dystonin-e-null mice described similar skin defects to those observed in humans but, unexpectedly, also showed severe neurodegeneration and dystonic symptoms [137]. While presentation of dystonin-e autoantigen in humans does not result in neurological deficits, BP patients have been reported to have an increased incidence of certain neurological diseases, such as multiple sclerosis, amyotrophic lateral sclerosis, Parkinson's disease, Alzheimer disease, and cerebral stroke [190-197]. While the reasons behind this correlation are unknown, it is interesting to speculate that mutations that affect other dystonin isoforms, such as dystonin-a may contribute to neurological symptoms observed in BP patients [197]. Indeed, in the reverse situation, an autoimmune response initially directed against neuronal dystonin-a triggered a secondary autoimmune response against dystonin-e based on their sequence homology [198-200]. Furthermore, in one human subject with a translocation in the human dystonin gene (DST) that specifically disrupted dystonin-a and -b isoforms, the patient presented with a profound delay in cognitive and motor function, as well as visual deficiency [39]. Curiously, no defect in epithelial tissue was observed, consistent with unaltered expression of the dystonin-e isoform. Thus, while no mutations in DST have been identified in humans, haploinsufficiency or altered expression can result in phenotypic abnormalities with some similarities to the inherited disorder in mice. 
TABLE 1: Mouse models of dystonia.

\begin{tabular}{|c|c|c|c|}
\hline Type/mutation & Anatomical phenotype & Motor phenotype & Reference \\
\hline \multicolumn{4}{|l|}{ Dystonin/Bpag1 mutations* } \\
\hline$d t^{24 J}$, spontaneous & Nervous system & Hind limb clasping, dystonia & {$[175]$} \\
\hline$d t^{27 J}$, spontaneous & Nervous system & Hind limb clasping, dystonia & {$[117]$} \\
\hline$d t^{a l b}$, spontaneous & Behavior, nervous system, muscle & Dystonia & {$[176]$} \\
\hline$d t^{I}$, spontaneous & $\begin{array}{l}\text { Mortality/aging, behavior, growth/size, } \\
\text { pigmentation, vision/eye, } \\
\text { hearing/vestibular/ear, integument }\end{array}$ & $\begin{array}{l}\text { Abnormal posture, ataxia, impaired } \\
\text { motor coordination }\end{array}$ & {$[177]$} \\
\hline $\begin{array}{l}d t^{T g 4}, \text { transgenic (random gene } \\
\text { disruption) }\end{array}$ & $\begin{array}{l}\text { Mortality/aging, behavior, nervous } \\
\text { system, muscle }\end{array}$ & $\begin{array}{l}\text { Impaired motor coordination, hind limb } \\
\text { clasping }\end{array}$ & {$[132]$} \\
\hline$d t^{t m 1 E f u}$, transgenic & $\begin{array}{l}\text { Mortality/aging, nervous system, muscle, } \\
\text { behavior, homeostasis, limbs/digits/tail, } \\
\text { integument }\end{array}$ & Dystonia & {$[178]$} \\
\hline \multicolumn{4}{|l|}{ DYT1 mutations ${ }^{\dagger}$} \\
\hline NSE-hMT, transgenic & $\begin{array}{l}\text { Perinuclear aggregates stained for torsin } \mathrm{A} \\
\text { and ubiquitin }\end{array}$ & $\begin{array}{l}\text { Hind limb clasping, marked } \\
\text { hyperactivity, circling }\end{array}$ & {$[21]$} \\
\hline CMV-hMT, transgenic & Not reported & $\begin{array}{l}\text { Limited improvement on repeated } \\
\text { rotarod testing in old animal }\end{array}$ & {$[165]$} \\
\hline Prion-hMT, transgenic & $\begin{array}{l}\text { Perinuclear aggregates stained for torsin } \mathrm{A} \\
\text { and ubiquitin }\end{array}$ & $\begin{array}{l}\text { Limited improvement on repeated } \\
\text { rotarod testing in old animals }\end{array}$ & {$[164]$} \\
\hline torsinA knock-in, heterozygous & $\begin{array}{l}\text { Perinuclear aggregates stained for torsin A } \\
\text { and ubiquitin, NE abnormalities in } \\
\text { neurons }\end{array}$ & $\begin{array}{l}\text { Mild hyperactivity, poor performance on } \\
\text { beam walking test }\end{array}$ & {$[23]$} \\
\hline torsinA knock-out, heterozygous & $\begin{array}{l}\text { Peduced amount of torsinA; NE } \\
\text { abnormalities in neurons }\end{array}$ & Similar to knock-in(heterozygous) & {$[96]$} \\
\hline $\begin{array}{l}\text { Cortex-specific torsinA knock-out, } \\
\text { heterozygous }\end{array}$ & Not reported & $\begin{array}{l}\text { Deficiency on beam-walking test, } \\
\text { hyperactivity }\end{array}$ & {$[98]$} \\
\hline TH- hMT, transgenic & Not reported & Similar to CMV-hMT, transgenic & {$[104]$} \\
\hline
\end{tabular}

NSE: neuron-specific enolase promoter; CMV: cytomegalovirus promoter; hMT: human torsinA mutant; hWT: human torsinA wild type; NE: nuclear envelope; TH: tyrosine hydroxylase.

* Based on information retrieved from the International Mouse Genome Database (MGI)

${ }^{\dagger}$ Adapted from Jinnah et al. [169].

\section{Similarities between Cellular Functions of TorsinA and Dystonin-a2}

5.1. Link between NE/ER and Cytoskeleton. Mutations in both mouse Dst and human TOR1A genes result in aberrations of NE/ER morphology. The homozygous knock-out and knock-in torsin $\mathrm{A} \Delta E$ mouse models of DYT1 dystonia show abnormalities in structure of the NE in embryos, largely confined to CNS neurons [25]. $d t$ mice also manifest nuclear eccentricity and loss of chromophilic material from around the nucleus in neurons in the red nucleus of the rostral midbrain and discrete regions of the striatum, likely due to perinuclear swelling and disorganization of the rough $\operatorname{ER}[35,41,179,185,201]$. Nuclear eccentricity has been reported for several $d t$ alleles and correlates with disease onset [37, 41]. Furthermore, mutation in dystonina2 results in accumulation of AFs around the nucleus and Golgi apparatus [136], which is in line with human DYT1 fibroblast in which has been shown nuclear accumulation of IF protein, vimentin [75].

In addition, torsin A and dystonin proteins have been attributed with roles in ER organization and ER stress.
Overexpression of wild-type torsin A has no marked effect on its ER distribution as compared with endogenous levels of torsinA, showing the typical reticular pattern throughout the cell body. In contrast, torsin $A \Delta E$ overexpression causes torsin A immunoreactivity to accumulate in the NE region $[13,15,16]$. Furthermore, overexpression of a truncated form of torsinA (torsinA313-332) initiates changes in ER macrostructure, resulting in a vacuolar distribution of both torsin A and protein disulfide isomerase (PDI) [58]. No TM proteins in the ER have been identified that interact with both torsinA and the cytoskeleton. However, protein processing in the ER depends on dynamic movement of membranes mediated by the cytoskeleton, especially in neurons [202]. While an association between torsinA and dystonin has not been demonstrated, the TM domain of dystonin-a 2 makes it an interesting candidate in this respect. Both proteins localize to the $\mathrm{ER}$ and $\mathrm{NE}$ and associate with nesprin-3 $\alpha$, as well as influence the structure of the NE and ER membranes, suggesting that these two proteins participate in common functional pathways.

Studies in $d t^{T g^{4}}$ mice have implicated mutations in Dst with ER-stress induction, based on upregulation of protein 
chaperones, PDI and binding immunoglobulin protein (BiP), also known as $78 \mathrm{kDa}$ glucose-regulated protein (GRP78) upon phenotypic onset of dystonia [41]. This suggests the possibility that disruption in the link between the ER and the cytoskeleton may initiate a proapoptotic signalling cascade in neurons of $d t$ mice initiated by ER stress. Similarly, torsinA-deficient mouse embryonic fibroblasts (MEFs) have increased ER stress, as compared to torsinA wild-type MEFs as detected by elevated BiP levels [87]. Furthermore, DYT1 fibroblasts elicit an ER stress response at lower concentrations of stress-inducing drugs as compared to fibroblasts from controls, and wild-type torsinA can reduce ER stress caused by ER protein overload in nematodes [58]. Recently, torsinA was found to coimmunoprecipitate with ERAD components, including Derlin-1, p97, and VIMP (VCP-interacting membrane protein), and downregulation of torsinA or expression of mutant torsin A compromised the cell's ability to eliminate mutant proteins from the ER [58]. Interestingly, torsin A and p97 have been found in inclusion bodies in brain and peripheral nerves of patients with a variety of neurodegenerative diseases, as well as dystonia suggesting their involvement in elimination or sequestration of toxic proteins [203-206]. Consistent with torsinA function in ERAD, it has also been found to be involved in quality control of $\varepsilon$-sarcoglycan (SGCE) processing [83], with SGCE expressed at high levels in the brain [207] and mutated in human myoclonic dystonia [208]. The involvement of torsin A in the ERAD pathway may help to explain the increased sensitivity of cells to ER stress following loss of or mutation in torsinA, with ER stress possibly contributing to onset of dystonia in DYT1 carriers $[58,86]$.

5.2. Nesprin-3 $\alpha$ : A Common Associated Partner of Dystonin-a2 and TorsinA. Nesprin proteins are evolutionarily conserved nuclear TM proteins that couple the NE with the cytoplasmic cytoskeleton (directly to MTs and AF and indirectly through plakins to IFs) [209]. Nesprin proteins possess a conserved 50 to 60 residue C-terminal KASH (Klarsicht, Anc-1, Syne Homology) domain featuring a single TM segment followed by a short lumenal sequence. To date four nesprin proteins have been identified [210]: nesprin1 (also known as Syne1, Myne-1, and Enaptin), nesprin-2 (also known as Syne2, Myne-2, and NUANCE), nesprin-3 and nesprin-4. For nesprins- 1 and -2 , the primary transcripts encode several alternatively spliced isoforms [170]. The largest of these, nesprin-1 Giant (Nesp1G; 1,000 kDa) as well as nesprin-2 Giant (Nesp2G; $800 \mathrm{kDa}$ ), reside in the ONM. Smaller isoforms may be found in the INM [211, 212]. The large flexible cytoplasmic domains of Nesp1G and Nesp2G each feature an N-terminal ABD followed by multiple SRs. Nesp1G and Nesp2G localize to the ONM via their KASH domain, which binds in the NE lumen to the INM domain of SUN proteins. These nesprins are able to form a link to the actin cytoskeleton through their calponin homology domains $[31,213]$. Nesprins are anchored in a similar way as SUN proteins but nesprin-3 interacts with IFs in the cytoplasm by binding to plectin [42]. Unlike nesprin- 1 and -2 , nesprin- 3 lacks an $\mathrm{ABD}$ domain and is

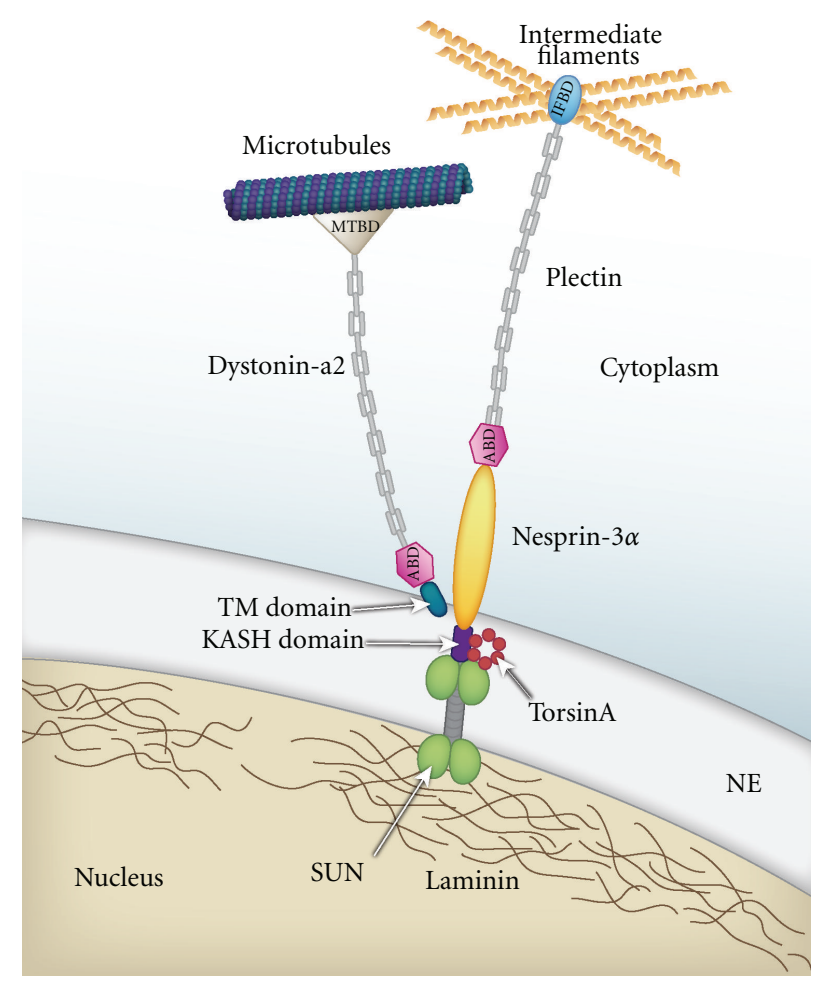

FIGURE 3: Hypothesized model for torsinA, dystonin-a2, and their common associated partner, nesprin- $3 \alpha$. This schematic represents the associations between torsinA and dystonin-a2 with nesprin-3 $\alpha$, a type II TM protein in the ONM that contains a C-terminal KASH domain within the lumenal space of the NE. Nesprin- $3 \alpha$ interacts with SUN proteins (green and gray), which span the INM of the $\mathrm{NE}$, through its KASH domain (purple). TorsinA (red hexameric circles) associates with nesprin- $3 \alpha$ and regulates its interaction with SUN proteins. The N-terminus of nesprin- $3 \alpha$ binds to the plakin family member, plectin, which in turn links to IFs through its IFbinding domain (IFBD; blue). Dystonin-a2 has a TM domain (dark blue) at the N-terminus, which embeds in the ONM of the NE and associates with nesprin-3 $\alpha$. Like plectin, dystonin-a isoforms are members of the plakin protein family and are characterized by SR domains indicated by the "chain shape" (gray) and an ABD (pink) in the $\mathrm{N}$-terminal region. The dystonin-a2 isoform also possesses a C-terminal MTBD through which it associates with microtubules. Collectively, these proteins function to bridge the NE and ER with the three major cytoskeleton networks present in eukaryotes.

therefore unable to associate with actin directly, but forms an interconnected mesh with AFs, MTs, and IFs through plakin family members, plectin isoforms, and dystonin-a2 [43, 214216], but it is unclear yet which isoform(s) is involved. Nesprin-3 has two splice variants, nesprin- $3 \alpha$ and nesprin$3 \beta$. Only nesprin- $3 \alpha$ contains an $\mathrm{N}$-terminal binding site for plectin that provides a bridge to IF cytoskeletal elements via C-terminal of plectins (Figure 3) [42]. Nesprin-4 has been identified as a kinesin-1-binding protein in the NE [210] and nesprin-1 binds kinesin-2, mediating the transport of membranes to the midbody of cells undergoing cytokinesis [217]. These findings suggest that other nesprins at the NE may also bind kinesins. Interestingly, nesprin-4 expression seems to be restricted mainly to secretory epithelia, where 
it may influence centrosome/nuclear positioning and the relationship of the Golgi apparatus to the nucleus [210].

Proteins linking the NE and cytoskeleton have been the subject of many investigations (for reviews see [218, $219])$. TorsinA has been shown to associate with a nesprin3 , plectin, and vimentin complex through its interaction with the KASH domain of nesprin [27]. The C-terminus of torsin A also associates with the KASH domain of nesprin-1 and nesprin-2. In the absence of torsin A, nesprin- 3 moves away from the nucleus into the ER [27]. Also, in DYT1 patient fibroblasts nesprin-3 accumulates in globular structures, presumably derived from the NE/ER, suggesting that mutant torsinA interferes with the interaction of nesprin3 with its binding partners in the NE [27]. We propose that both dystonin and torsin A influence the interaction between the NE and cytoskeleton through their association with nesprins in the ONM (Figure 3).

The association between dystonin-a2 and nesprin- $3 \alpha$ highlights their role in linking the NE/ER to the cytoskeleton (Figure 3). The common modular structure between plectin isoforms and dystonin-a implicates the $\mathrm{ABD}$ as a critical mediator of interactions between multiple proteins and nesprin-3 $\alpha$. Two-hybrid analysis revealed that the $\mathrm{ABD}$ of dystonin-a facilitates interaction with nesprin-3 $\alpha$ [42]. Furthermore, studies have elucidated the dystonin isoforms involved in this interaction, with dystonin-a2 (ABD and $\mathrm{TM}$ ), but not isoform a3 (ABD only), being coimmunoprecipitated with nesprin-3 $\alpha$ [41]. This association was attributed to the TM domain adjacent to the $\mathrm{ABD}$ at the $\mathrm{N}$ terminus of dystonin-a2 that uniquely positions the protein near perikaryal membranes.

\section{Conclusions}

TorsinA and dystonin-a2 share many features, including causing neurologic diseases with a dystonic phenotype when mutated in humans and mice, respectively, with the onset of symptoms occurring at a young age. Although DYT1 dystonia is inherited as an autosomal dominant disease and $d t$ dystonia in mice as an autosomal recessive disease, both represent a decrease or loss of function, respectively, of the normal wild-type protein. Both proteins are associated with the NE and ER. While torsinA remains in the contiguous lumen shared by the NE and ER, dystonin-a2 is a cytoplasmic protein associated with NE/ER, as well as Golgi membranes. Both torsin A and dystonin-a2 have been found to be associated with nesprin- $3 \alpha$, which forms a link between the ONM of the NE and the cytoskeleton, with mutated versions of both proteins causing abnormal morphology of the NE and formation of perinuclear inclusions involving cytoskeletal proteins. Loss of function of both proteins is associated with increased sensitivity to ER stress, which can cause cellular dysfunction and/or lead to neuronal apoptosis.

Torsin A and dystonin-a2 are both critical to neuronal functions, albeit in different neuronal subpopulations. Although DYT1 dystonia is primarily a disease of the brain without marked neurodegeneration and $d t$ dystonia affects primarily peripheral sensory and motor neurons with neu- rodegeneration, there is evidence that some areas of the brain are also affected by Dst mutations. A distinct difference between diseases caused by mutations in these two proteins is the early death of $d t$ mice, while DYT1 patients have few, if any, other medical problems related to their dystonia. Both proteins have been implicated in a variety of cellular processes, including processing of proteins through secretory pathways, transport of organelles along neuronal processes, and cell migration. Their broad involvement in cellular mechanisms can be explained by their interaction with the cytoskeleton, which is critical in many cellular processes. Thus, dystonin-a2 and torsinA share similar functions, and the reason they affect different neuronal populations presumably reflects their differential expression in specific neuronal subtypes. Dystonin-a2 is primarily expressed in sensory and motor neurons in the peripheral nervous system, whereas torsin A is mainly expressed in specific neurons in the CNS. Understanding their common functions supports the critical role of NE/ER cytoskeletal interactions in maintaining neuronal integrity and function, with dysfunction at many levels of the nervous system contributing to abnormal dystonic movements.

\section{Abbreviations}

$\mathrm{AAA}^{+}$:

Superfamily of ATPases associated with diverse cellular activities

ATPases/proteins: Enzyme that catalyses the hydrolysis adenosine triphosphate

ABD:

AF:

BP:

BPAG1:

bpag1:

C. elegans:

CNS:

DA:

$\triangle E:$

DST:

Dst:

$d t:$

DYT1:

EB1:

Actin-binding domain

Actin filament

Bullous pemphigoid

Bullous pemphigoid antigen 1

Mouse bullous pemphigoid

antigen 1

Caenorhabditis elegans

Central nervous system

Dopamine

Deletion of glutamic acid

Human dystonin gene

Mouse dystonin gene

Dystonia musculorum

Early-onset, torsion dystonia

Microtubule end-binding

protein 1

ER:

ERAD:

Gas2:

IF:

IFBD:

INM:

Hypb:

Endoplasmic reticulum

ER-associated degradation

growth arrest-specific 2

Intermediate filament

IF-binding domain

Inner nuclear membrane

Hydrophobic amino terminal

domain

KASH: Klarsicht, ANC-1, Syne

homology

LAP1: $\quad$ Lamina-associated polypeptide 


$\begin{array}{ll}\text { LINC: } & \begin{array}{l}\text { Linker of nucleoskeleton and } \\ \text { cytoskeleton complex }\end{array} \\ \text { LULL1: } & \text { Lumenal domain like LAP1 } \\ \text { MACF1: } & \begin{array}{l}\text { Microtubule actin cross-linking } \\ \text { factor 1 }\end{array} \\ \text { MEFs: } & \text { Mouse embryonic fibroblasts } \\ \text { MT: } & \text { Microtubule } \\ \text { MTBD: } & \text { MT binding domain } \\ \text { myr: } & \text { Myristylation motif } \\ \text { NE: } & \text { nuclear envelope } \\ \text { Nesp1G: } & \text { Nesprin-1 Giant } \\ \text { Nesp2G: } & \text { Nesprin-2 Giant } \\ \text { nesprins: } & \text { Nuclear envelope spectrin repeat } \\ \text { NF: } & \text { Neurofilament } \\ \text { ONM: } & \text { Outer nuclear membrane } \\ \text { PDI: } & \text { Protein disulfide isomerase } \\ \text { SGCE: } & \mathcal{E} \text {-sarcoglycan } \\ \text { SS: } & \text { Signal sequence } \\ \text { SRs: } & \text { Spectrin repeats } \\ \text { SUN1: } & \text { Sad1 and UNC84 domain } \\ \text { TM: } & \text { containing 1 } \\ \text { TOR1A; previously } & \text { Transmembrane domain } \\ \text { referred to as DYT1: } & \text { human gene encoding torsinA } \\ \text { TOR2: } & \text { Torsin2 gene } \\ \text { TOR3: } & \text { Torsin3 gene } \\ \text { VIMP: } & \text { VCP-interacting membrane } \\ & \text { protein. } \\ & \end{array}$

\section{Acknowledgments}

The authors thank Professor C. J. F. van Noorden for his helpful review comments, corrections, and criticisms, Ms. Suzanne McDavitt for skilled editorial assistance, and Ms. Emily Mills (Millstone Design; http://www.millstone-design .com) for preparation of Figure 3. This work was supported by NIH/NINDS Grant NS037409 (XOB); Canadian Institutes of Health Research (CIHR) Grant 12622 (RK), in partnership with the Dystonia Medical Research Foundation of Canada Fellowship (SDR); Parkinson's and Movement Disorder Foundation and Harvard Medical School, The Eleanor and Miles Shore 50th Anniversary Fellowship Program for Scholars in Medicine (FCN); AMC Medical/Graduate School Ph.D. Scholarships, University of Amsterdam, The Netherlands (NAA).

\section{References}

[1] S. Fahn, "Concept and classification of dystonia," Advances in Neurology, vol. 50, pp. 1-8, 1988.

[2] H. L. Geyer and S. B. Bressman, "The diagnosis of dystonia," The Lancet Neurology, vol. 5, no. 9, pp. 780-790, 2006.

[3] D. G. Standaert, "Update on the pathology of dystonia," Neurobiology of Disease, vol. 42, no. 2, pp. 148-151, 2011.

[4] D. C. Bragg, I. A. Armata, F. C. Nery, X. O. Breakefield, and N. Sharma, "Molecular pathways in dystonia," Neurobiology of Disease, vol. 42, pp. 136-147, 2011.

[5] N. Brüggemann and C. Klein, "Genetics of primary torsion dystonia," Current Neurology and Neuroscience Reports, vol. 10, no. 3, pp. 199-206, 2010.
[6] L. J. Ozelius, J. W. Hewett, C. E. Page et al., "The early-onset torsion dystonia gene (DYT1) encodes an ATP-binding protein," Nature Genetics, vol. 17, no. 1, pp. 40-48, 1997.

[7] L. W. Duchen, D. S. Falconer, and S. J. Strich, "Dystonia musculorum. A hereditary neuropathy of mice affecting mainly sensory pathways," The Journal of Physiology, vol. 165, pp. 79, 1963.

[8] A. Brown, G. Bernier, M. Mathieu, J. Rossant, and R. Kothary, "The mouse Dystonia musculorum gene is a neural isoform of bullous pemphigoid antigen 1," Nature Genetics, vol. 10, no. 3, pp. 301-306, 1995.

[9] S. B. Bressman, C. Sabatti, D. Raymond et al., "The DYT1 phenotype and guidelines for diagnostic testing," Neurology, vol. 54, no. 9, pp. 1746-1752, 2000.

[10] J. C. O. Leung, C. Klein, J. Friedman et al., "Novel mutation in the TOR1A [DYT1] gene in atypical, early onset dystonia and polymorphisms in dystonia and early onset parkinsonism," Neurogenetics, vol. 3, no. 3, pp. 133-143, 2001.

[11] N. Calakos, V. D. Patel, M. Gottron et al., "Functional evidence implicating a novel TOR1A mutation in idiopathic, late-onset focal dystonia," Journal of Medical Genetics, vol. 47, no. 9, pp. 646-650, 2010.

[12] B. Zirn, K. Grundmann, P. Huppke et al., "Novel TOR1A mutation p.Arg288Gln in early-onset dystonia (DYT1)," Journal of Neurology, Neurosurgery and Psychiatry, vol. 79, no. 12, pp. 1327-1330, 2008.

[13] J. Hewett, C. Gonzalez-Agosti, D. Slater et al., "Mutant torsin A, responsible for early-onset torsion dystonia, forms membrane inclusions in cultured neural cells," Human Molecular Genetics, vol. 9, no. 9, pp. 1403-1413, 2000.

[14] P. Gonzalez-Alegre and H. L. Paulson, "Aberrant cellular behavior of mutant TorsinA implicates nuclear envelope dysfunction in DYT1 dystonia," Journal of Neuroscience, vol. 24, no. 11, pp. 2593-2601, 2004.

[15] R. E. Goodchild and W. T. Dauer, "Mislocalization to the nuclear envelope: an effect of the dystonia-causing torsinA mutation," Proceedings of the National Academy of Sciences of the United States of America, vol. 101, no. 3, pp. 847-852, 2004.

[16] T. V. Naismith, J. E. Heuser, X. O. Breakefield, and P. I. Hanson, "Torsin A in the nuclear envelope," Proceedings of the National Academy of Sciences of the United States of America, vol. 101, no. 20, pp. 7612-7617, 2004.

[17] J. C. Hedreen, R. M. Zweig, M. R. DeLong, P. J. Whitehouse, and D. L. Price, "Primary dystonias: a review of the pathology and suggestions for new directions of study," Advances in Neurology, vol. 50, pp. 123-132, 1988.

[18] R. H. Walker, M. F. Brin, D. Sandu, P. F. Good, and P. Shashidharan, "TorsinA immunoreactivity in brains of patients with DYT1 and non-DYT1 dystonia," Neurology, vol. 58, no. 1, pp. 120-124, 2002.

[19] K. Rostasy, S. J. Augood, J. W. Hewett et al., “TorsinA protein and neuropathology in early onset generalized dystonia with GAG deletion," Neurobiology of Disease, vol. 12, no. 1, pp. 1124, 2003.

[20] K. S. P. McNaught, A. Kapustin, T. Jackson et al., "Brainstem pathology in DYT1 primary torsion dystonia," Annals of Neurology, vol. 56, no. 4, pp. 540-547, 2004.

[21] P. Shashidharan, D. Sandu, U. Potla et al., "Transgenic mouse model of early-onset DYT1 dystonia," Human Molecular Genetics, vol. 14, no. 1, pp. 125-133, 2005.

[22] A. Granata, G. Schiavo, and T. T. Warner, "TorsinA and dystonia: from nuclear envelope to synapse," Journal of Neurochemistry, vol. 109, no. 6, pp. 1596-1609, 2009. 
[23] M. T. Dang, F. Yokoi, K. S. P. McNaught et al., "Generation and characterization of Dyt1 $\triangle \mathrm{gAG}$ knock-in mouse as a model for early-onset dystonia," Experimental Neurology, vol. 196, no. 2, pp. 452-463, 2005.

[24] R. E. Goodchild, C. E. Kim, and W. T. Dauer, "Loss of the dystonia-associated protein torsinA selectively disrupts the neuronal nuclear envelope," Neuron, vol. 48, no. 6, pp. 923932, 2005.

[25] R. E. Goodchild and W. T. Dauer, "The $\mathrm{AAA}^{+}$protein torsinA interacts with a conserved domain present in LAP1 and a novel ER protein," Journal of Cell Biology, vol. 168, no. 6, pp. 855-862, 2005.

[26] M. T. Jungwirth, D. Kumar, D. Y. Jeong, and R. E. Goodchild, "The nuclear envelope localization of DYT1 dystonia torsinA- $\Delta \mathrm{E}$ requires the SUN1 LINC complex component," BMC Cell Biology, vol. 12, article 24, 2011.

[27] F. C. Nery, J. Zeng, B. P. Niland et al., "TorsinA binds the $\mathrm{KASH}$ domain of nesprins and participates in linkage between nuclear envelope and cytoskeleton," Journal of Cell Science, vol. 121, no. 20, pp. 3476-3486, 2008.

[28] L. Powell and B. Burke, "Internuclear exchange of an inner nuclear membrane protein (p55) in heterokaryons: in vivo evidence for the interaction of p55 with the nuclear lamina," Journal of Cell Biology, vol. 111, no. 6, pp. 2225-2234, 1990.

[29] C. E. Kim, A. Perez, G. Perkins, M. H. Ellisman, and W. T. Dauer, "A molecular mechanism underlying the neuralspecific defect in torsinA mutant mice," Proceedings of the National Academy of Sciences of the United States of America, vol. 107, no. 21, pp. 9861-9866, 2010.

[30] M. Crisp, Q. Liu, K. Roux et al., "Coupling of the nucleus and cytoplasm: role of the LINC complex," Journal of Cell Biology, vol. 172, no. 1, pp. 41-53, 2006.

[31] F. Haque, D. J. Lloyd, D. T. Smallwood et al., "SUN1 interacts with nuclear lamin A and cytoplasmic nesprins to provide a physical connection between the nuclear lamina and the cytoskeleton," Molecular and Cellular Biology, vol. 26, no. 10, pp. 3738-3751, 2006.

[32] D. Razafsky and D. Hodzic, "Bringing KASH under the SUN: the many faces of nucleo-cytoskeletal connections," Journal of Cell Biology, vol. 186, no. 4, pp. 461-472, 2009.

[33] W. Lu, J. Gotzmann, L. Sironi et al., "Sun1 forms immobile macromolecular assemblies at the nuclear envelope," Biochimica et Biophysica Acta, vol. 1783, no. 12, pp. 2415-2426, 2008.

[34] J. A. Mellad, D. T. Warren, and C. M. Shanahan, "Nesprins LINC the nucleus and cytoskeleton," Current Opinion in Cell Biology, vol. 23, pp. 47-54, 2011.

[35] L. W. Duchen, S. J. Strich, and D. S. Falconer, "Clinical and pathological studies of an hereditary neuropathy in mice (Dystonia musculorum)," Brain, vol. 87, no. 2, pp. 367-378, 1964.

[36] J. Dowling, Y. Yang, R. Wollmann, L. F. Reichardt, and E. Fuchs, "Developmental expression of BPAG-n: insights into the spastic ataxia and gross neurologic degeneration in Dystonia musculorum mice," Developmental Biology, vol. 187, no. 2, pp. 131-142, 1997.

[37] Y. de Repentigny, A. Ferrier, S. D. Ryan, T. Sato, and R. Kothary, "Motor unit abnormalities in Dystonia musculorum mice," PLoS ONE, vol. 6, no. 6, article e21093, 2011.

[38] J. R. Stanley, "Cell adhesion molecules as targets of autoantibodies in pemphigus and pemphigoid, bullous diseases due to defective epidermal cell adhesion," Advances in Immunology, vol. 53, pp. 291-326, 1993.
[39] R. Giorda, A. Cerritello, M. C. Bonaglia et al., "Selective disruption of muscle and brain-specific BPAG1 isoforms in a girl with a 6;15 translocation, cognitive and motor delay, and tracheo-oesophageal atresia," Journal of Medical Genetics, vol. 41, no. 6, article e71, 2004.

[40] R. W. Groves, L. Liu, P. J. Dopping-Hepenstal et al., "A homozygous nonsense mutation within the dystonin gene coding for the coiled-coil domain of the epithelial isoform of BPAG1 underlies a new subtype of autosomal recessive epidermolysis bullosa simplex," Journal of Investigative Dermatology, vol. 130, no. 6, pp. 1551-1557, 2010.

[41] K. G. Young and R. Kothary, "Dystonin/Bpag1 is a necessary endoplasmic reticulum/nuclear envelope protein in sensory neurons," Experimental Cell Research, vol. 314, no. 15, pp. 2750-2761, 2008.

[42] K. Wilhelmsen, S. H. M. Litjens, I. Kuikman et al., "Nesprin3 , a novel outer nuclear membrane protein, associates with the cytoskeletal linker protein plectin," Journal of Cell Biology, vol. 171, no. 5, pp. 799-810, 2005.

[43] G. Wiche, "Role of plectin in cytoskeleton organization and dynamics," Journal of Cell Science, vol. 111, no. 17, pp. 24772486, 1998.

[44] L. J. Ozelius, J. W. Hewett, C. E. Page et al., "The gene (DYT1) for early-onset torsion dystonia encodes a novel protein related to the Clp protease/heat shock family," Advances in Neurology, vol. 78, pp. 93-105, 1998.

[45] A. F. Neuwald, L. Aravind, J. L. Spouge, and E. V. Koonin, "AAA : a class of chaperone-like ATPases associated with the assembly, operation, and disassembly of protein complexes," Genome Research, vol. 9, no. 1, pp. 27-43, 1999.

[46] P. I. Hanson and S. W. Whiteheart, "AAA ${ }^{+}$proteins: have engine, will work," Nature Reviews Molecular Cell Biology, vol. 6, no. 7, pp. 519-529, 2005.

[47] M. Nagy, H. C. Wu, Z. Liu, S. Kedzierska-Mieszkowska, and M. Zolkiewski, "Walker-A threonine couples nucleotide occupancy with the chaperone activity of the AAA ${ }^{+}$ATPase ClpB," Protein Science, vol. 18, no. 2, pp. 287-293, 2009.

[48] F. Confalonieri and M. Duguet, "A 200-amino acid ATPase module in search of a basic function," BioEssays, vol. 17, no. 7, pp. 639-650, 1995.

[49] A. Beyer, "Sequence analysis of the AAA protein family," Protein Science, vol. 6, no. 10, pp. 2043-2058, 1997.

[50] H. R. Waterham and J. M. Cregg, "Peroxisome biogenesis," BioEssays, vol. 19, no. 1, pp. 57-66, 1997.

[51] S. Subramani, "Components involved in peroxisome import, biogenesis, proliferation, turnover, and movement," Physiological Reviews, vol. 78, no. 1, pp. 171-188, 1998.

[52] L. Zhu, J. O. Wrabl, A. P. Hayashi, L. S. Rose, and P. J. Thomas, "The torsin-family $\mathrm{AAA}^{+}$protein OOC- 5 contains a critical disulfide adjacent to sensor-II that couples redox state to nucleotide binding," Molecular Biology of the Cell, vol. 19, no. 8, pp. 3599-3612, 2008.

[53] N. Kock, T. V. Naismith, H. E. Boston et al., "Effects of genetic variations in the dystonia protein torsinA: identification of polymorphism at residue 216 as protein modifier," Human Molecular Genetics, vol. 15, no. 8, pp. 1355-1364, 2006.

[54] L. Zhu, L. Millen, J. L. Mendoza, and P. J. Thomas, “A unique redox-sensing sensor II motif in torsina plays a critical role in nucleotide and partner binding," The Journal of Biological Chemistry, vol. 285, no. 48, pp. 37271-37280, 2010.

[55] X. O. Breakefield, C. Kamm, and P. I. Hanson, "TorsinA: movement at many levels," Neuron, vol. 31, no. 1, pp. 9-12, 2001. 
[56] D. A. Dougan, D. Micevski, and K. N. Truscott, "The Nend rule pathway: from recognition by $\mathrm{N}$-recognins, to destruction by $\mathrm{AAA}^{+}$proteases," Biochimica et Biophysica Acta, vol. 1823, no. 1, pp. 83-91, 2012.

[57] T. Ravid and M. Hochstrasser, "Diversity of degradation signals in the ubiquitin-proteasome system," Nature Reviews Molecular Cell Biology, vol. 9, no. 9, pp. 679-689, 2008.

[58] F. C. Nery, I. A. Armata, J. E. Farley et al., "TorsinA participates in endoplasmic reticulum-associated degradation," Nature Communications, vol. 2, no. 1, article 393, 2011.

[59] L. J. Ozelius, C. E. Page, C. Klein et al., "The TOR1A (DYT1) gene family and its role in early onset torsion dystonia," Genomics, vol. 62, no. 3, pp. 377-384, 1999.

[60] M. Jungwirth, M. L. Dear, P. Brown, K. Holbrook, and R. Goodchild, "Relative tissue expression of homologous tor$\sin B$ correlates with the neuronal specific importance of DYT1 dystonia-associated torsinA," Human Molecular Genetics, vol. 19, no. 5, pp. 888-900, 2010.

[61] K. Kabakci, K. Hedrich, J. C. Leung et al., "Mutations in DYT1: extension of the phenotypic and mutational spectrum," Neurology, vol. 62, no. 3, pp. 395-400, 2004.

[62] N. J. Risch, S. B. Bressman, G. Senthil, and L. J. Ozelius, "Intragenic Cis and Trans modification of genetic susceptibility in DYT1 torsion dystonia," American Journal of Human Genetics, vol. 80, no. 6, pp. 1188-1193, 2007.

[63] J. W. Hewett, C. Kamm, H. Boston et al., "TorsinB-perinuclear location and association with torsinA," Journal of Neurochemistry, vol. 89, no. 5, pp. 1186-1194, 2004.

[64] K. Kustedjo, M. H. Bracey, and B. F. Cravatt, "Torsin A and its torsion dystonia-associated mutant forms are lumenal glycoproteins that exhibit distinct subcellular localizations," The Journal of Biological Chemistry, vol. 275, no. 36, pp. 27933-27939, 2000.

[65] A. C. Callan, S. Bunning, O. T. Jones, S. High, and E. Swanton, "Biosynthesis of the dystonia-associated $\mathrm{AAA}^{+}$ATPase torsinA at the endoplasmic reticulum," Biochemical Journal, vol. 401, no. 2, pp. 607-612, 2007.

[66] C. O'Farrell, P. J. Lockhart, S. Lincoln et al., "Biochemical characterization of torsinB," Molecular Brain Research, vol. 127, no. 1-2, pp. 1-9, 2004.

[67] J. Xiao, S. Gong, Y. Zhao, and M. S. LeDoux, "Developmental expression of rat torsinA transcript and protein," Developmental Brain Research, vol. 152, no. 1, pp. 47-60, 2004.

[68] A. Vasudevan, X. O. Breakefield, and P. G. Bhide, "Developmental patterns of torsinA and torsinB expression," Brain Research, vol. 1073-1074, no. 1, pp. 139-145, 2006.

[69] S. J. Augood, J. B. Penney Jr., I. K. Friberg et al., "Expression of the early onset torsion dystonia gene (DYT1) in human brain," Annals of Neurology, vol. 43, no. 5, pp. 669-673, 1998.

[70] S. J. Augood, D. M. Martin, L. J. Ozelius, X. O. Breakefield, J. B. Penney, and D. G. Standaert, "Distribution of the mRNAs encoding torsin A and torsinB in the normal adult human brain," Annals of Neurology, vol. 46, no. 5, pp. 761-769, 1999.

[71] S. J. Augood, Z. R. Hollingsworth, D. G. Standaert, P. C. Emson, and J. B. Penney, "Localization of dopaminergic markers in the human subthalamic nucleus," Journal of Comparative Neurology, vol. 421, no. 2, pp. 247-255, 2000.

[72] M. Konakova, D. P. Huynh, W. Yong, and S. M. Pulst, "Cellular distribution of torsin A and torsin B in normal human brain," Archives of Neurology, vol. 58, no. 6, pp. 921-927, 2001.

[73] A. Granata and T. T. Warner, "The role of torsinA in dystonia," European Journal of Neurology, vol. 17, no. 1, supplement, pp. 81-87, 2010.
[74] C. Kamm, H. Boston, J. Hewett et al., "The early onset dystonia protein torsin A interacts with kinesin light chain 1," The Journal of Biological Chemistry, vol. 279, no. 19, pp. 19882-19892, 2004.

[75] J. W. Hewett, J. Zeng, B. P. Niland, D. C. Bragg, and X. O. Breakefield, "Dystonia-causing mutant torsinA inhibits cell adhesion and neurite extension through interference with cytoskeletal dynamics," Neurobiology of Disease, vol. 22, no. 1, pp. 98-111, 2006

[76] G. Ferrari-Toninelli, S. Paccioretti, S. Francisconi, D. Uberti, and M. Memo, "TorsinA negatively controls neurite outgrowth of SH-SY5Y human neuronal cell line," Brain Research, vol. 1012, no. 1-2, pp. 75-81, 2004.

[77] S. E. Basham and L. S. Rose, "The Caenorhabditis elegans polarity gene ooc-5 encodes a Torsin-related protein of the AAA ATPase superfamily," Development, vol. 128, no. 22, pp. 4645-4656, 2001.

[78] P. J. McLean, H. Kawamata, S. Shariff et al., "TorsinA and heat shock proteins act as molecular chaperones: suppression of $\alpha$-synuclein aggregation," Journal of Neurochemistry, vol. 83, no. 4 , pp. 846-854, 2002.

[79] G. A. Caldwell, S. Cao, E. G. Sexton, C. C. Gelwix, J. P. Bevel, and K. A. Caldwell, "Suppression of polyglutamineinduced protein aggregation in Caenorhabditis elegans by torsin proteins," Human Molecular Genetics, vol. 12, no. 3, pp. 307-319, 2003.

[80] N. I. Muraro and K. G. Moffat, "Down-regulation of torp4a, encoding the Drosophila homologue of torsinA, results in increased neuronal degeneration," Journal of Neurobiology, vol. 66, no. 12, pp. 1338-1353, 2006.

[81] T. V. Naismith, S. Dalal, and P. I. Hanson, "Interaction of torsin A with its major binding partners is impaired by the dystonia-associated $\triangle \mathrm{GAG}$ deletion," The Journal of Biological Chemistry, vol. 284, no. 41, pp. 27866-27874, 2009.

[82] A. J. Burdette, P. F. Churchill, G. A. Caldwell, and K. A. Caldwell, "The early-onset torsion dystonia-associated protein, torsinA, displays molecular chaperone activity in vitro," Cell Stress and Chaperones, vol. 15, no. 5, pp. 605-617, 2010.

[83] C. T. Esapa, A. Waite, M. Locke et al., "SGCE missense mutations that cause myoclonus-dystonia syndrome impair $\mathcal{\varepsilon}$ sarcoglycan trafficking to the plasma membrane: modulation by ubiquitination and torsinA," Human Molecular Genetics, vol. 16, no. 3, pp. 327-342, 2007.

[84] J. Hewett, P. Ziefer, D. Bergeron et al., “TorsinA in PC12 cells: localization in the endoplasmic reticulum and response to stress," Journal of Neuroscience Research, vol. 72, no. 2, pp. 158-168, 2003.

[85] M. J. Baptista, C. O'Farrell, J. Hardy, and M. R. Cookson, "Microarray analysis reveals induction of heat shock proteins mRNAs by the torsion dystonia protein, TorsinA," Neuroscience Letters, vol. 343, no. 1, pp. 5-8, 2003.

[86] P. Chen, A. J. Burdette, J. C. Porter et al., "The early-onset torsion dystonia-associated protein, torsin A, is a homeostatic regulator of endoplasmic reticulum stress response," Human Molecular Genetics, vol. 19, no. 18, pp. 3502-3515, 2010.

[87] K. L. Gordon, K. A. Glenn, and P. Gonzalez-Alegre, "Exploring the influence of TorsinA expression on protein quality control," Neurochemical Research, vol. 63, pp. 452-459, 2011.

[88] J. W. Hewett, B. Tannous, B. P. Niland et al., "Mutant tor$\sin \mathrm{A}$ interferes with protein processing through the secretory pathway in DYT1 dystonia cells," Proceedings of the National Academy of Sciences of the United States of America, vol. 104, no. 17, pp. 7271-7276, 2007. 
[89] J. W. Hewett, F. C. Nery, B. Niland et al., "siRNA knock-down of mutant torsinA restores processing through secretory pathway in DYT1 dystonia cells," Human Molecular Genetics, vol. 17, no. 10, pp. 1436-1445, 2008.

[90] L. Jossé, C. Mark Smales, and M. F. Tuite, "Transient expression of human TorsinA enhances secretion of two functionally distinct proteins in cultured chinese hamster ovary (CHO) cells," Biotechnology and Bioengineering, vol. 105, no. 3, pp. 556-566, 2010.

[91] A. Granata, R. Watson, L. M. Collinson, G. Schiavo, and T. T. Warner, "The dystonia-associated protein TorsinA modulates synaptic vesicle recycling," The Journal of Biological Chemistry, vol. 283, no. 12, pp. 7568-7579, 2008.

[92] A. Granata, S. J. Koo, V. Haucke, G. Schiavo, and T. T. Warner, "CSN complex controls the stability of selected synaptic proteins via a torsinA-dependent process," EMBO Journal, vol. 30, no. 1, pp. 181-193, 2011.

[93] G. E. Torres, A. L. Sweeney, J. M. Beaulieu, P. Shashidharan, and M. G. Caron, "Effect of torsinA on membrane proteins reveals a loss of function and a dominant-negative phenotype of the dystonia-associated $\Delta \mathrm{E}$-torsinA mutant," Proceedings of the National Academy of Sciences of the United States of America, vol. 101, no. 44, pp. 15650-15655, 2004.

[94] S. Cao, C. C. Gelwix, K. A. Caldwell, and G. A. Caldwell, "Torsin-mediated protection from cellular stress in the dopaminergic neurons of Caenorhabditis elegans," Journal of Neuroscience, vol. 25, no. 15, pp. 3801-3812, 2005.

[95] A. Pisani, G. Martella, A. Tscherter et al., "Altered responses to dopaminergic $\mathrm{D} 2$ receptor activation and $\mathrm{N}$-type calcium currents in striatal cholinergic interneurons in a mouse model of DYT1 dystonia," Neurobiology of Disease, vol. 24, no. 2, pp. 318-325, 2006.

[96] M. T. Dang, F. Yokoi, M. A. Pence, and Y. Li, "Motor deficits and hyperactivity in Dyt1 knockdown mice," Neuroscience Research, vol. 56, no. 4, pp. 470-474, 2006.

[97] A. Balcioglu, M. O. Kim, N. Sharma, J. H. Cha, X. O. Breakefield, and D. G. Standaert, "Dopamine release is impaired in a mouse model of DYT1 dystonia," Journal of Neurochemistry, vol. 102, no. 3, pp. 783-788, 2007.

[98] F. Yokoi, M. T. Dang, S. Mitsui, J. Li, and Y. Li, "Motor deficits and hyperactivity in cerebral cortex-specific Dyt1 conditional knockout mice," Journal of Biochemistry, vol. 143, no. 1, pp. 39-47, 2008.

[99] Y. Zhao, J. Xiao, M. Ueda et al., "Glial elements contribute to stress-induced torsin A expression in the CNS and peripheral nervous system," Neuroscience, vol. 155, no. 2, pp. 439-453, 2008.

[100] G. Sciamanna, P. Bonsi, A. Tassone et al., "Impaired striatal D2 receptor function leads to enhanced GABA transmission in a mouse model of DYT1 dystonia," Neurobiology of Disease, vol. 34, no. 1, pp. 133-145, 2009.

[101] C. A. O'Farrell, K. L. Martin, M. Hutton, M. B. Delatycki, M. R. Cookson, and P. J. Lockhart, "Mutant torsinA interacts with tyrosine hydroxylase in cultured cells," Neuroscience, vol. 164, no. 3, pp. 1127-1137, 2009.

[102] J. Hewett, P. Johanson, N. Sharma, D. Standaert, and A. Balcioglu, "Function of dopamine transporter is compromised in DYT1 transgenic animal model in vivo," Journal of Neurochemistry, vol. 113, no. 1, pp. 228-235, 2010.

[103] F. Napolitano, M. Pasqualetti, A. Usiello et al., "Dopamine D2 receptor dysfunction is rescued by adenosine A2A receptor antagonism in a model of DYT1 dystonia," Neurobiology of Disease, vol. 38, no. 3, pp. 434-445, 2010.
[104] M. E. Page, L. Bao, P. Andre et al., "Cell-autonomous alteration of dopaminergic transmission by wild type and mutant $(\Delta \mathrm{E})$ TorsinA in transgenic mice," Neurobiology of Disease, vol. 39, no. 3, pp. 318-326, 2010.

[105] G. Sciamanna, A. Tassone, G. Martella et al., "Developmental profile of the aberrant dopamine D2 receptor response in striatal cholinergic interneurons in DYT1 dystonia," PLoS ONE, vol. 6, no. 9, article e24261, 2011.

[106] F. Yokoi, M. T. Dang, J. Li, D. G. Standaert, and Y. Li, “Motor deficits and decreased striatal dopamine receptor 2 binding activity in the striatum-specific Dyt1 conditional knockout mice," PLoS ONE, vol. 6, no. 9, article e24539, 2011.

[107] N. Wakabayashi-Ito, O. M. Doherty, H. Moriyama et al., "Dtorsin, the Drosophila ortholog of the early-onset dystonia TOR1A (DYT1), plays a novel role in dopamine metabolism," PLoS ONE, vol. 6, no. 10, article e26183, 2011.

[108] E. Bahn, S. Siegert, T. Pfander et al., "TorsinB expression in the developing human brain," Brain Research, vol. 1116, no. 1, pp. 112-119, 2006.

[109] M. Dron, J. F. Meritet, F. Dandoy-Dron, J. P. Meyniel, C. Maury, and M. G. Tovey, "Molecular cloning of ADIR, a novel interferon responsive gene encoding a protein related to the torsins," Genomics, vol. 79, no. 3, pp. 315-325, 2002.

[110] Y. H. Koh, K. Rehfeld, and B. Ganetzky, "A Drosophila model of early onset torsion dystonia suggests impairment in TGF$\beta$ signaling," Human Molecular Genetics, vol. 13, no. 18, pp. 2019-2030, 2004.

[111] S. E. Basham and L. S. Rose, "Mutations in ooc-5 and ooc-3 disrupt oocyte formation and the reestablishment of asymmetric PAR protein localization in two-cell Caenorhabditis elegans embryos," Developmental Biology, vol. 215, no. 2, pp. 253-263, 1999.

[112] E. Fuchs and I. Karakesisoglou, "Bridging cytoskeletal intersections," Genes and Development, vol. 15, no. 1, pp. 1-14, 2001.

[113] G. Bernier, Y. De Repentigny, M. Mathieu, S. David, and R. Kothary, "Dystonin is an essential component of the Schwann cell cytoskeleton at the time of myelination," Development, vol. 125, no. 11, pp. 2135-2148, 1998.

[114] A. Sonnenberg and R. K. H. Liem, "Plakins in development and disease," Experimental Cell Research, vol. 313, no. 10, pp. 2189-2203, 2007.

[115] J. J. Jefferson, C. Ciatto, L. Shapiro, and R. K. H. Liem, "Structural analysis of the plakin domain of bullous pemphigoid antigen1 (BPAG1) suggests that plakins are members of the spectrin superfamily," Journal of Molecular Biology, vol. 366, no. 1, pp. 244-257, 2007.

[116] A. Brown, G. Dalpe, M. Mathieu, and R. Kothary, "Cloning and characterization of the neural isoforms of human dystonin," Genomics, vol. 29, no. 3, pp. 777-780, 1995.

[117] G. Bernier, M. Mathieu, Y. De Repentigny, S. M. Vidal, and R. Kothary, "Cloning and characterization of mouse ACF7, a novel member of the dystonin subfamily of actin binding proteins," Genomics, vol. 38, no. 1, pp. 19-29, 1996.

[118] C. L. Leung, D. Sun, M. Zheng, D. R. Knowles, and R. K. H. Liem, "Microtubule actin cross-linking factor (MACF): a hybrid of dystonin and dystrophin that can interact with the actin and microtubule cytoskeletons," Journal of Cell Biology, vol. 147, no. 6, pp. 1275-1285, 1999.

[119] C. M. Lin, H. J. Chen, C. L. Leung, D. A. D. Parry, and R. K. H. Liem, "Microtubule actin crosslinking factor 1b: a novel plakin that localizes to the Golgi complex," Journal of Cell Science, vol. 118, no. 16, pp. 3727-3738, 2005. 
[120] S. Kazerounian, J. Uitto, and S. Aho, "Unique role for the periplakin tail in intermediate filament association: specific binding to keratin 8 and vimentin," Experimental Dermatology, vol. 11, no. 5, pp. 428-438, 2002.

[121] C. L. Leung, R. K. H. Liem, D. A. D. Parry, and K. J. Green, "The plakin family," Journal of Cell Science, vol. 114, no. 19, pp. 3409-3410, 2001.

[122] G. Burgstaller, M. Gregor, L. Winter, and G. Wiche, "Keeping the vimentin network under control: cell-matrix adhesionassociated plectin If affects cell shape and polarity of fibroblasts," Molecular Biology of the Cell, vol. 21, no. 19, pp. 33623375, 2010.

[123] K. Röper, S. L. Gregory, and N. H. Brown, "The " spectraplakins" cytoskeletal giants with characteristics of both spectrin and plakin families," Journal of Cell Science, vol. 115, no. 22, pp. 4215-4225, 2002.

[124] G. Bernier, A. Brown, G. Dalpé, M. Mathieu, Y. De Repentigny, and R. Kothary, "Dystonin transcripts are altered and their levels are reduced in the mouse neurological mutant dt24J," Biochemistry and Cell Biology, vol. 73, no. 9-10, pp. 605-609, 1995.

[125] D. Goryunov, C. Z. He, C. S. Lin, C. L. Leung, and R. K. H. Liem, "Nervous-tissue-specific elimination of microtubuleactin crosslinking factor 1a results in multiple developmental defects in the mouse brain," Molecular and Cellular Neuroscience, vol. 44, no. 1, pp. 1-14, 2010.

[126] D. Selcen, V. C. Juel, L. D. Hobson-Webb et al., "Myasthenic syndrome caused by plectinopathy," Neurology, vol. 76, no. 4, pp. 327-336, 2011.

[127] K. Djinovic-Carugo, M. Gautel, J. Ylänne, and P. Young, “The spectrin repeat: a structural platform for cytoskeletal protein assemblies," FEBS Letters, vol. 513, no. 1, pp. 119-123, 2002.

[128] C. L. Leung, M. Zheng, S. M. Prater, and R. K. H. Liem, "The BPAG1 locus: alternative splicing produces multiple isoforms with distinct cytoskeletal linker domains, including predominant isoforms in neurons and muscles," Journal of Cell Biology, vol. 154, no. 4, pp. 691-697, 2001.

[129] D. Sun, C. L. Leung, and R. K. H. Liem, "Characterization of the microtubule binding domain of microtubule actin crosslinking factor (MACF): identification of a novel group of microtubule associated proteins," Journal of Cell Science, vol. 114, no. 1, pp. 161-172, 2001.

[130] M. Okumura, H. Yamakawa, O. Ohara, and K. Owaribe, "Novel alternative splicings of BPAG1 (bullous pemphigoid antigen 1) including the domain structure closely related to MACF (microtubule actin cross-linking factor)," The Journal of Biological Chemistry, vol. 277, no. 8, pp. 6682-6687, 2002.

[131] D. Sawamura, K. Li, M. L. Chu, and J. Uitto, "Human bullous pemphigoid antigen (BPAG1): amino acid sequences deduced from cloned cDNAs predict biologically important peptide segments and protein domains," The Journal of Biological Chemistry, vol. 266, no. 27, pp. 17784-17790, 1991.

[132] R. Kothary, S. Clapoff, A. Brown, R. Campbell, A. Peterson, and J. Rossant, "A transgene containing lacZ inserted into the dystonia locus is expressed in neural tube," Nature, vol. 335, no. 6189, pp. 435-437, 1988.

[133] M. Pool, C. B. Larivière, G. Bernier, K. G. Young, and R. Kothary, "Genetic alterations at the Bpag1 locus in $\mathrm{dt}$ mice and their impact on transcript expression," Mammalian Genome, vol. 16, no. 12, pp. 909-917, 2005.

[134] K. G. Young and R. Kothary, "Dystonin/Bpag1-a link to what?" Cell Motility and the Cytoskeleton, vol. 64, no. 12, pp. 897-905, 2007.
[135] J. J. Jefferson, C. L. Leung, and R. K. H. Liem, "Dissecting the sequence specific functions of alternative $\mathrm{N}$-terminal isoforms of mouse bullous pemphigoid antigen 1," Experimental Cell Research, vol. 312, no. 15, pp. 2712-2725, 2006.

[136] K. G. Young, B. Pinheiro, and R. Kothary, "A Bpag1 isoform involved in cytoskeletal organization surrounding the nucleus," Experimental Cell Research, vol. 312, no. 2, pp. 121134, 2006.

[137] L. Guo, L. Degenstein, J. Bowling et al., "Gene targeting of BPAG1: abnormalities in mechanical strength and cell migration in stratified epithelia and neurologic degeneration," Cell, vol. 81, no. 2, pp. 233-243, 1995.

[138] S. Lee and P. A. Kolodziej, "Short stop provides an essential link between F-actin and microtubules during axon extension,” Development, vol. 129, no. 5, pp. 1195-1204, 2002.

[139] D. A. Applewhite, K. D. Grode, D. Keller, A. Zadeh, K. C. Slep, and S. L. Rogers, "The spectraplakin short stop is an actinmicrotubule cross-linker that contributes to organization of the microtubule network," Molecular Biology of the Cell, vol. 21, no. 10, pp. 1714-1724, 2010.

[140] A. Kodama, I. Karakesisoglou, E. Wong, A. Vaezi, and E. Fuchs, "ACF7: an essential integrator of microtubule dynamics," Cell, vol. 115, no. 3, pp. 343-354, 2003.

[141] K. C. Slep, S. L. Rogers, S. L. Elliott, H. Ohkura, P. A. Kolodziej, and R. D. Vale, "Structural determinants for EB1mediated recruitment of APC and spectraplakins to the microtubule plus end," Journal of Cell Biology, vol. 168, no. 4, pp. 587-598, 2005.

[142] S. Rivero, J. Cardenas, M. Bornens, and R. M. Rios, "Microtubule nucleation at the cis-side of the golgi apparatus requires AKAP450 and GM130," EMBO Journal, vol. 28, no. 8, pp. 1016-1028, 2009.

[143] J. E. Dominguez, B. Buendia, C. Lopez-Otin, C. Antony, E. Karsenti, and J. Avila, "A protein related to brain microtubule-associated protein MAP1B is a component of the mammalian centrosome," Journal of Cell Science, vol. 107, no. 2, pp. 601-611, 1994.

[144] A. E. Radulescu and D. Shields, "Clathrin is required for postmitotic Golgi reassembly," FASEB Journal, vol. 26, no. 1, pp. 129-136, 2012.

[145] K. Bhanot, K. G. Young, and R. Kothary, "MAP1B and clathrin are novel interacting partners of the giant cyto-linker dystonin," Journal of Proteome Research, vol. 10, no. 11, pp. 5118-5127, 2011.

[146] B. Bisel, Y. Wang, J. H. Wei et al., "ERK regulates Golgi and centrosome orientation towards the leading edge through GRASP65," Journal of Cell Biology, vol. 182, no. 5, pp. 837843, 2008.

[147] P. M. Miller, A. W. Folkmann, A. R. R. Maia, N. Efimova, A. Efimov, and I. Kaverina, "Golgi-derived CLASP-dependent microtubules control Golgi organization and polarized trafficking in motile cells," Nature Cell Biology, vol. 11, no. 9, pp. 1069-1080, 2009.

[148] A. Meixner, S. Haverkamp, H. Wässle et al., "MAP1B is required for axon guidance and is involved in the development of the central and peripheral nervous system," Journal of Cell Biology, vol. 151, no. 6, pp. 1169-1178, 2000.

[149] J. Teng, Y. Takei, A. Harada, T. Nakata, J. Chen, and N. Hirokawa, "Synergistic effects of MAP2 and MAP1B knockout in neuronal migration, dendritic outgrowth, and microtubule organization," Journal of Cell Biology, vol. 155, no. 1, pp. 65-76, 2001. 
[150] J. J. Liu, J. Ding, A. S. Kowal et al., "BPAG1n4 is essential for retrograde axonal transport in sensory neurons," Journal of Cell Biology, vol. 163, no. 2, pp. 223-229, 2003.

[151] J. J. Liu, J. Ding, C. Wu et al., "Retrolinkin, a membrane protein, plays an important role in retrograde axonal transport," Proceedings of the National Academy of Sciences of the United States of America, vol. 104, no. 7, pp. 2223-2228, 2007.

[152] Y. De Repentigny, J. Deschênes-Furry, B. J. Jasmin, and R. Kothary, "Impaired fast axonal transport in neurons of the sciatic nerves from Dystonia musculorum mice," Journal of Neurochemistry, vol. 86, no. 3, pp. 564-571, 2003.

[153] K. B. Boylan, J. H. Chin, and S. J. DeArmond, "Progressive dystonia following resuscitation from cardiac arrest," Neurology, vol. 40, no. 9, pp. 1458-1461, 1990.

[154] G. F. Wooten, M. B. S. Lopes, W. O. Harris, T. J. Reagan, and S. R. Vandenberg, "Pallidoluysian atrophy: dystonia and basal ganglia functional anatomy," Neurology, vol. 43, no. 9, pp. 1764-1768, 1993.

[155] M. S. Lee and C. D. Marsden, "Movement disorders following lesions of the thalamus or subthalamic region," Movement Disorders, vol. 9, no. 5, pp. 493-507, 1994.

[156] R. S. Raike, H. A. Jinnah, and E. J. Hess, "Animal models of generalized dystonia," NeuroRx, vol. 2, no. 3, pp. 504-512, 2005.

[157] H. A. Jinnah and E. J. Hess, "A new twist on the anatomy of dystonia: the basal ganglia and the cerebellum?" Neurology, vol. 67 , no. 10, pp. 1740-1741, 2006.

[158] A. O. Ceballos-Baumann, R. E. Passingham, T. Warner, E. D. Playford, C. D. Marsden, and D. J. Brooks, "Overactive prefrontal and underactive motor cortical areas in idiopathic dystonia," Annals of Neurology, vol. 37, no. 3, pp. 363-372, 1995.

[159] T. Odergren, S. Stone-Elander, and M. Ingvar, "Cerebral and cerebellar activation in correlation to the action-induced dystonia in writer's cramp," Movement Disorders, vol. 13, no. 3, pp. 497-508, 1998.

[160] C. Preibisch, D. Berg, E. Hofmann, L. Solymosi, and M. Naumann, "Cerebral activation patterns in patients with writer's cramp: a functional magnetic resonance imaging study," Journal of Neurology, vol. 248, no. 1, pp. 10-17, 2001.

[161] M. Hutchinson, T. Nakamura, J. R. Moeller et al., "The metabolic topography of essential blepharospasm: a focal dystonia with general implications," Neurology, vol. 55, no. 5, pp. 673$677,2000$.

[162] I. Le Ber, F. Clot, L. Vercueil et al., "Predominant dystonia with marked cerebellar atrophy: a rare phenotype in familial dystonia," Neurology, vol. 67, no. 10, pp. 1769-1773, 2006.

[163] G. Bernier, A. Brown, G. Dalpe, Y. De Repentigny, M. Mathieu, and R. Kothary, "Dystonin expression in the developing nervous system predominates in the neurons that degenerate in Dystonia musculorum mutant mice," Molecular and Cellular Neurosciences, vol. 6, no. 6, pp. 509-520, 1995.

[164] K. Grundmann, B. Reischmann, G. Vanhoutte et al., "Overexpression of human wildtype torsin A and human $\triangle \mathrm{GAG}$ torsinA in a transgenic mouse model causes phenotypic abnormalities," Neurobiology of Disease, vol. 27, no. 2, pp. 190206, 2007.

[165] N. Sharma, M. G. Baxter, J. Petravicz et al., "Impaired motor learning in mice expressing torsinA with the DYT1 dystonia mutation," Journal of Neuroscience, vol. 25, no. 22, pp. 53515355, 2005.

[166] J. F. Lorden, G. A. Oltmans, S. Stratton, and L. E. Mays, "Neuropharmacological correlates of the motor syndrome of the genetically dystonic (dt) rat," Advances in Neurology, vol. 50, pp. 277-297, 1988.

[167] J. F. Lorden, S. E. Stratton, L. E. Mays, and G. A. Oltmans, "Purkinje cell activity in rats following chronic treatment with harmaline," Neuroscience, vol. 27, no. 2, pp. 465-472, 1988.

[168] V. K. Neychev, X. Fan, V. I. Mitev, E. J. Hess, and H. A. Jinnah, "The basal ganglia and cerebellum interact in the expression of dystonic movement," Brain, vol. 131, no. 9, pp. 2499-2509, 2008.

[169] H. A. Jinnah, A. Richter, J. W. Mink et al., "Animal models for drug discovery in dystonia," Expert Opinion on Drug Discovery, vol. 3, no. 1, pp. 83-97, 2008.

[170] L. Zhang, F. Yokoi, Y. H. Jin et al., "Altered dendritic morphology of Purkinje cells in DYT1 $\delta$ GAG knock-in and Purkinje cell-specific DYT1 conditional knockout mice," PLoS ONE, vol. 6, no. 3, article e18357, 2011.

[171] M. S. LeDoux, J. F. Lorden, and J. M. Ervin, "Cerebellectomy eliminates the motor syndrome of the genetically dystonic rat," Experimental Neurology, vol. 120, no. 2, pp. 302-310, 1993.

[172] M. S. LeDoux, J. F. Lorden, and J. Meinzen-Derr, "Selective elimination of cerebellar output in the genetically dystonic rat," Brain Research, vol. 697, no. 1-2, pp. 91-103, 1995.

[173] L. C. Abbott, M. Bump, A. Brandl, and S. De Laune, "Investigation of the role of the cerebellum in the myoclonic-like movement disorder exhibited by tottering mice," Movement Disorders, vol. 15, no. 1, pp. 53-59, 2000.

[174] D. B. Campbell, J. B. North, and E. J. Hess, “Tottering mouse motor dysfunction is abolished on the Purkinje cell degeneration (pcd) mutant background," Experimental Neurology, vol. 160, no. 1, pp. 268-278, 1999.

[175] R. T. Bronson, H. O. Sweet, C. A. Spencer, and M. T. Davisson, "Genetic and age related models of neurodegeneration in mice: dystrophic axons," Journal of Neurogenetics, vol. 8, no. 2, pp. 71-83, 1992.

[176] A. Messer and D. Gordon, "Changes in whole tissue biosynthesis of $\gamma$-amino butyric acid (GABA) in basal ganglia of the dystonia (dt(Alb)) mouse," Life Sciences, vol. 25, no. 26, pp. 2217-2221, 1979.

[177] L. W. Duchen, "“Sprawling”: a new mutant mouse with failure of myelination of sensory axons and a deficiency of muscle spindles," Neuropathology and Applied Neurobiology, vol. 1, no. 1, pp. 89-101, 1975.

[178] A. Brown, N. Lemieux, J. Rossant, and R. Kothary, "Human homolog of a mouse sequence from the Dystonia musculorum locus is on chromosome 6p12," Mammalian Genome, vol. 5, no. 7, pp. 434-437, 1994.

[179] C. Sotelo and J. L. Guenet, "Pathologic changes in the CNS of Dystonia musculorum mutant mouse: an animal model for human spinocerebellar ataxia," Neuroscience, vol. 27, no. 2, pp. 403-424, 1988.

[180] C. L. Leung, D. Sun, and R. K. H. Liem, "The intermediate filament protein peripherin is the specific interaction partner of mouse BPAG1-n (dystonin) in neurons," Journal of Cell Biology, vol. 144, no. 3, pp. 435-446, 1999.

[181] K. W. Tseng, Y. P. Chau, M. F. Yang, K. S. Lu, and C. L. Chien, "Abnormal cellular translocation of $\alpha$-internexin in spinal motor neurons of Dystonia musculorum mice," Journal of Comparative Neurology, vol. 507, no. 1, pp. 1053-1064, 2008.

[182] K. W. Tseng, K. S. Lu, and C. L. Chien, "A possible cellular mechanism of neuronal loss in the dorsal root ganglia of 
Dystonia musculorum (dt) mice," Journal of Neuropathology and Experimental Neurology, vol. 65, no. 4, pp. 336-347, 2006.

[183] G. Bernier and R. Kothary, "Prenatal onset of axonopathy in Dystonia musculorum mice," Developmental Genetics, vol. 22, no. 2, pp. 160-168, 1998.

[184] G. Dalpé, M. Mathieu, A. Comtois et al., "Dystonin-deficient mice exhibit an intrinsic muscle weakness and an instability of skeletal muscle cytoarchitecture," Developmental Biology, vol. 210, no. 2, pp. 367-380, 1999.

[185] A. Messer and N. L. Strominger, "An allele of the mouse mutant Dystonia musculorum exhibits lesions in red nucleus and striatum," Neuroscience, vol. 5, no. 3, pp. 543-549, 1980.

[186] H. A. Jinnah, K. Egami, L. Rao, M. Shin, S. Kasim, and E. J. Hess, "Expression of c-fos in the Brain after Activation of L-Type Calcium Channels," Developmental Neuroscience, vol. 25, no. 6, pp. 403-411, 2003.

[187] O. Bousquet and P. A. Coulombe, "Cytoskeleton: missing links found?” Current Biology, vol. 6, no. 12, pp. 1563-1566, 1996.

[188] W. H. Irwin McLean, L. Pulkkinen, F. J. D. Smith et al., "Loss of plectin causes epidermolysis bullosa with muscular dystrophy: cDNA cloning and genomic organization," Genes and Development, vol. 10, no. 14, pp. 1724-1735, 1996.

[189] F. J. D. Smith, R. A. J. Eady, I. M. Leigh et al., "Plectin deficiency results in muscular dystrophy with epidermolysis bullosa," Nature Genetics, vol. 13, no. 4, pp. 450-457, 1996.

[190] K. Gebauer, J. Cox, J. Gartside, and T. Navaratnam, "Bullous pemphigoid and multiple sclerosis," Journal of the American Academy of Dermatology, vol. 23, no. 2, p. 329, 1990.

[191] G. Kirtschig, V. M. Walkden, V. A. Venning, and F. Wojnarowska, "Bullous pemphigoid and multiple sclerosis: a report of three cases and review of the literature," Clinical and Experimental Dermatology, vol. 20, no. 6, pp. 449-453, 1995.

[192] N. Foureur, V. Descamps, B. Lebrun-Vignes et al., "Bullous pemphigoid in a leg affected with hemiparesia: a possible relation of neurological diseases with bullous pemphigoid?" European Journal of Dermatology, vol. 11, no. 3, pp. 230-233, 2001.

[193] A. Forschner, A. Ulmer, G. Rassner, and G. Fierlbeck, "Bullous pemphigoid in a patient with Parkinson's disease," European Journal of Dermatology, vol. 12, no. 6, p. 615, 2002.

[194] G. Stinco, P. Mattighello, M. Zanchi, and P. Patrone, "Multiple sclerosis and bullous pemphigoid: a casual association or a pathogenetic correlation?" European Journal of Dermatology, vol. 12, no. 2, pp. 186-188, 2002.

[195] G. Stinco, R. Codutti, M. Scarbolo, F. Valent, and P. Patrone, "A retrospective epidemiological study on the association of bullous pemphigoid and neurological diseases," Acta Dermato-Venereologica, vol. 85, no. 2, pp. 136-139, 2005.

[196] C. Bouras, B. M. Riederer, E. Kövari, P. R. Hof, and P. Giannakopoulos, "Humoral immunity in brain aging and Alzheimer's disease," Brain Research Reviews, vol. 48, no. 3, pp. 477-487, 2005.

[197] J. Chen, L. Li, J. Chen et al., "Sera of elderly bullous pemphigoid patients with associated neurological diseases recognize bullous pemphigoid antigens in the human brain," Gerontology, vol. 57, pp. 211-216, 2011.

[198] E. Laffitte, P. R. Burkhard, L. Fontao et al., "Bullous pemphigoid antigen 1 isoforms: potential new target autoantigens in multiple sclerosis?" British Journal of Dermatology, vol. 152, no. 3, pp. 537-540, 2005.

[199] S. Bastuji-Garin, P. Joly, P. Lemordant et al., "Risk factors for bullous pemphigoid in the elderly: a prospective case-control study," Journal of Investigative Dermatology, vol. 131, no. 3, pp. 637-643, 2011.

[200] J. A. Fairley, D. T. Woodley, M. Chen, G. J. Giudice, and M. S. Lin, "A patient with both bullous pemphigoid and epidermolysis bullosa acquisita: an example of intermolecular epitope spreading," Journal of the American Academy of Dermatology, vol. 51, no. 1, pp. 118-122, 2004.

[201] J. S. Hanker and R. Peach, "Histochemical and ultrastructural studies of primary sensory neurons in mice with Dystonia musculorum. I Acetylcholinesterase and lysosomal hydrolases," Neuropathology and Applied Neurobiology, vol. 2, no. 2, pp. 79-97, 1976.

[202] J. I. Valenzuela, M. Jaureguiberry-Bravo, and A. Couve, "Neuronal protein trafficking: emerging consequences of endoplasmic reticulum dynamics," Molecular and Cellular Neuroscience, vol. 48, no. 4, pp. 269-277, 2011.

[203] L. Zhao and S. L. Ackerman, "Endoplasmic reticulum stress in health and disease," Current Opinion in Cell Biology, vol. 18, no. 4, pp. 444-452, 2006.

[204] N. Sharma, J. Hewett, L. J. Ozelius et al., "A close association of torsinA and $\alpha$-synuclein in lewy bodies: a fluorescence resonance energy transfer study," American Journal of Pathology, vol. 159, no. 1, pp. 339-344, 2001.

[205] R. H. Walker, P. F. Good, and P. Shashidharan, "Torsin A immunoreactivity in inclusion bodies in trinucleotide repeat diseases," Movement Disorders, vol. 18, no. 9, pp. 1041-1044, 2003.

[206] G. D. J. Watts, J. Wymer, M. J. Kovach et al., "Inclusion body myopathy associated with Paget disease of bone and frontotemporal dementia is caused by mutant valosin-containing protein," Nature Genetics, vol. 36, no. 4, pp. 377-381, 2004.

[207] K. Ritz, B. D. van Schaik, M. E. Jakobs et al., "SGCE isoform characterization and expression in human brain: implications for myoclonus-dystonia pathogenesis?" European Journal of Human Genetics, vol. 19, pp. 438-444, 2011.

[208] F. Asmus, F. Salih, L. E. Hjermind et al., "Myoclonus-dystonia due to genomic deletions in the epsilon-sarcoglycan gene," Annals of Neurology, vol. 58, no. 5, pp. 792-797, 2005.

[209] D. A. Starr, "Communication between the cytoskeleton and the nuclear envelope to position the nucleus," Molecular BioSystems, vol. 3, no. 9, pp. 583-589, 2007.

[210] K. J. Roux, M. L. Crisp, Q. Liu et al., "Nesprin 4 is an outer nuclear membrane protein that can induce kinesin-mediated cell polarization," Proceedings of the National Academy of Sciences of the United States of America, vol. 106, no. 7, pp. 21942199, 2009.

[211] J. M. K. Mislow, J. M. Holaska, M. S. Kim et al., "Nesprin-1 $\alpha$ self-associates and binds directly to emerin and lamin A in vitro," FEBS Letters, vol. 525, no. 1-3, pp. 135-140, 2002.

[212] Q. Zhang, C. D. Ragnauth, J. N. Skepper et al., "Nespirin-2 is a multi-isomeric protein that binds lamin and emerin at the nuclear envelope and forms a subcellular network in skeletal muscle," Journal of Cell Science, vol. 118, no. 4, pp. 673-687, 2005.

[213] V. C. Padmakumar, T. Libotte, W. Lu et al., "The inner nuclear membrane protein Sun 1 mediates the anchorage of Nesprin-2 to the nuclear envelope," Journal of Cell Science, vol. 118, no. 15, pp. 3419-3430, 2005.

[214] K. Wilhelmsen, M. Ketema, H. Truong, and A. Sonnenberg, "KASH-domain proteins in nuclear migration, anchorage and other processes," Journal of Cell Science, vol. 119, no. 24, pp. 5021-5029, 2006. 
[215] L. Chang and R. D. Goldman, "Intermediate filaments mediate cytoskeletal crosstalk," Nature Reviews Molecular Cell Biology, vol. 5, no. 8, pp. 601-613, 2004.

[216] H. Herrmann, H. Bär, L. Kreplak, S. V. Strelkov, and U. Aebi, "Intermediate filaments: from cell architecture to nanomechanics," Nature Reviews Molecular Cell Biology, vol. 8, no. 7, pp. 562-573, 2007.

[217] J. Fan and K. A. Beck, "A role for the spectrin superfamily member syne-1 and kinesin II in cytokinesis," Journal of Cell Science, vol. 117, no. 4, pp. 619-629, 2004.

[218] L. Gerace, "TorsinA and torsion dystonia: unraveling the architecture of the nuclear envelope," Proceedings of the $\mathrm{Na}$ tional Academy of Sciences of the United States of America, vol. 101, no. 24, pp. 8839-8840, 2004.

[219] H. J. Worman and G. G. Gundersen, "Here come the SUNs: a nucleocytoskeletal missing link," Trends in Cell Biology, vol. 16, no. 2, pp. 67-69, 2006. 

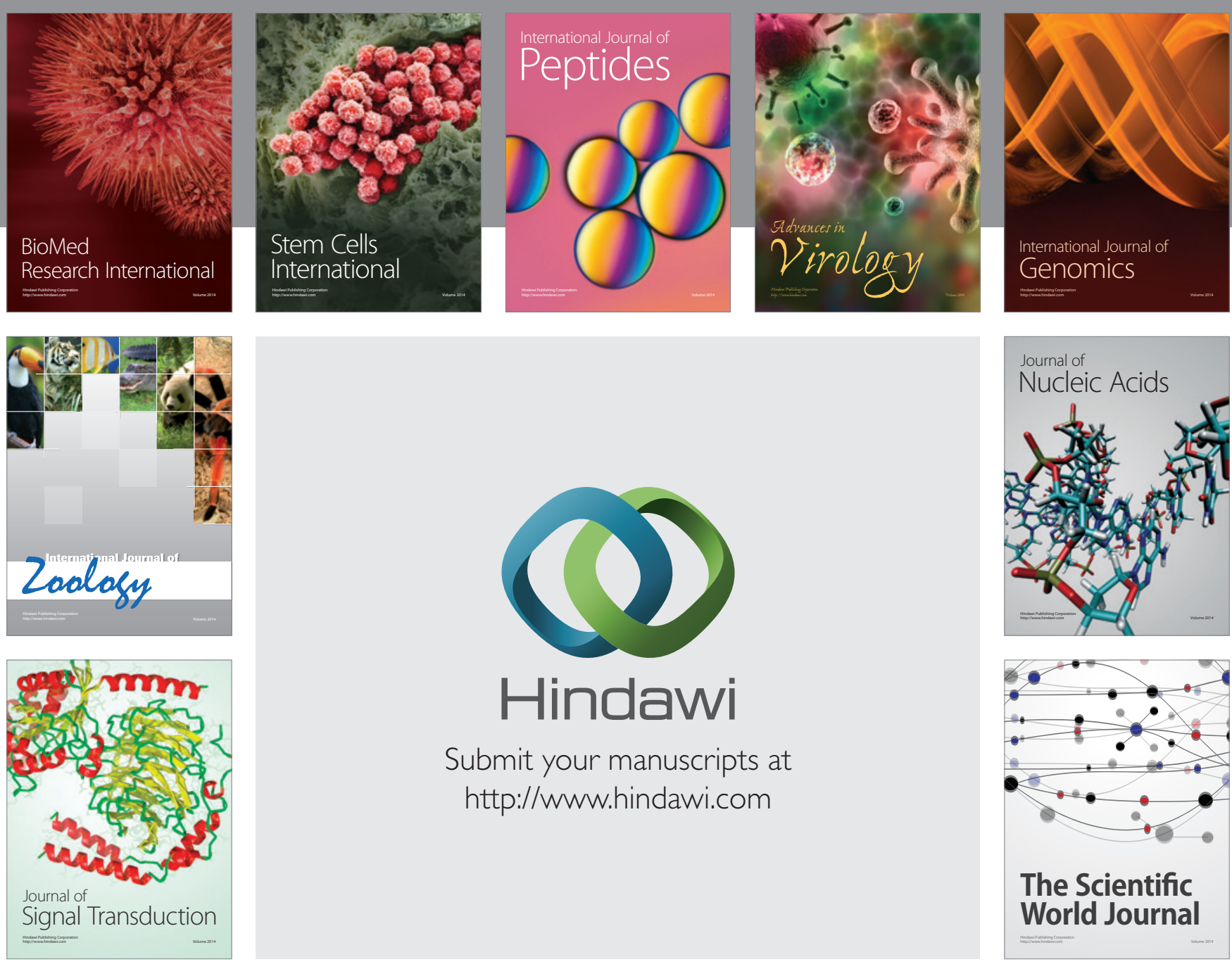

Submit your manuscripts at

http://www.hindawi.com
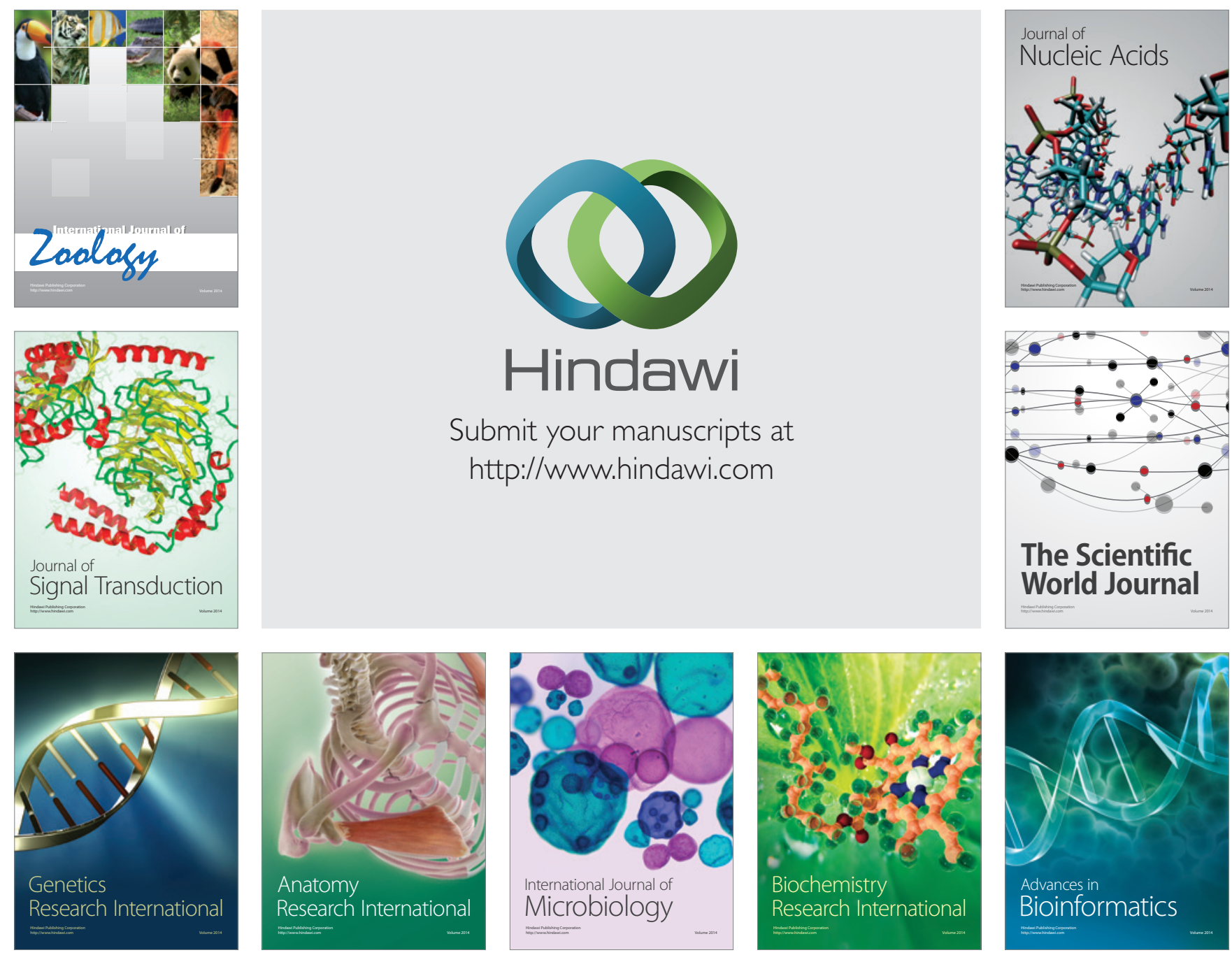

The Scientific World Journal
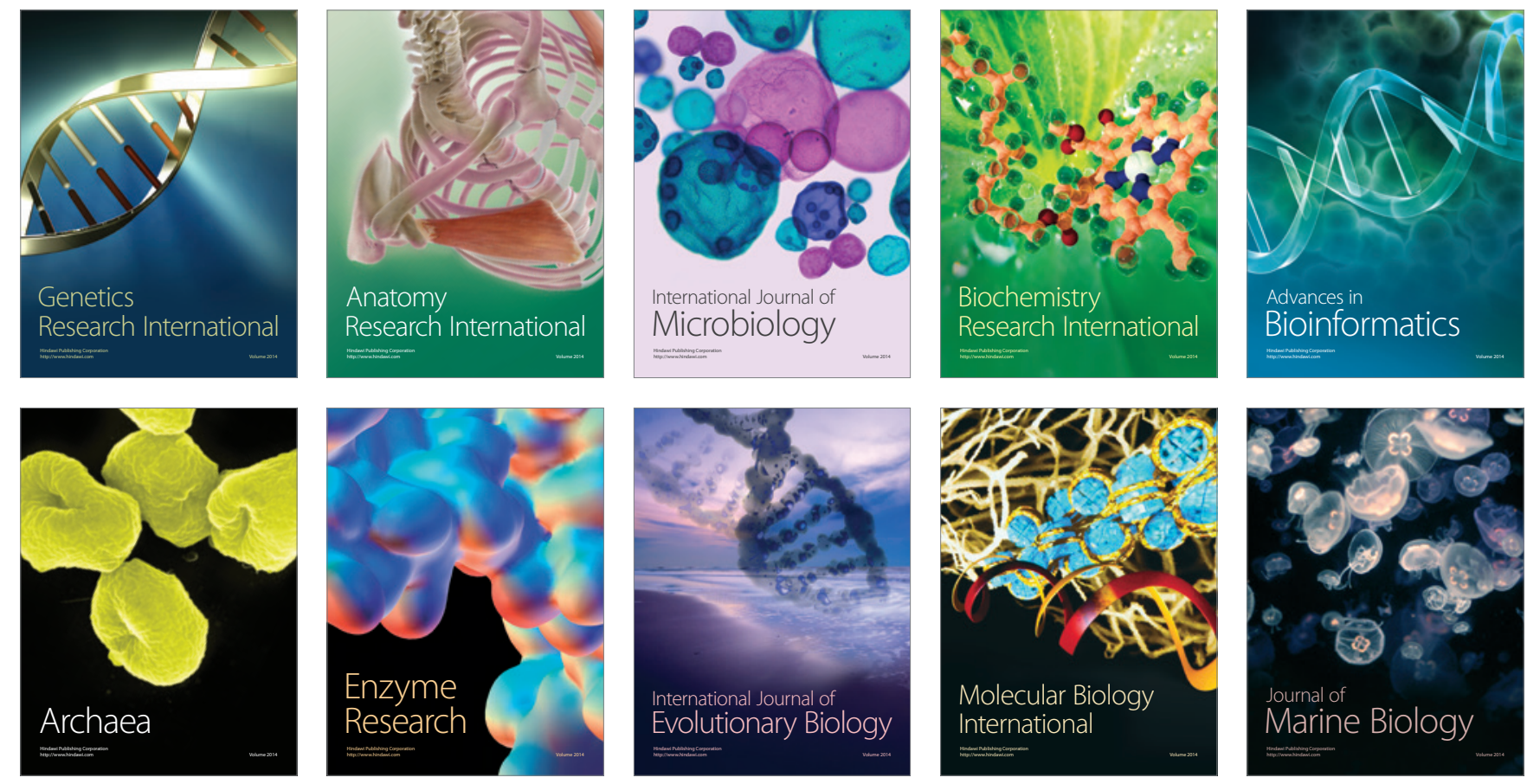